Research Article

\title{
Experimental Study of Composite Members in Spatial Grid Structure Subjected to Ultralow-Cyclic Axial Force
}

\author{
Jie Zhang $\mathbb{D},{ }^{1,2}$ Haiwang $L i\left(\mathbb{D},{ }^{1}\right.$ and Xiayun Song ${ }^{1}$ \\ ${ }^{1}$ College of Civil Engineering, Taiyuan University of Technology, Taiyuan 030024, China \\ ${ }^{2}$ Shanxi Conservancy Technical Institute, Taiyuan 030024, China \\ Correspondence should be addressed to Haiwang Li; lhwtut@126.com
}

Received 2 September 2019; Revised 25 November 2019; Accepted 19 December 2019; Published 22 January 2020

Academic Editor: Rosario Montuori

Copyright (c) 2020 Jie Zhang et al. This is an open access article distributed under the Creative Commons Attribution License, which permits unrestricted use, distribution, and reproduction in any medium, provided the original work is properly cited.

This paper presents the results of ultralow-cycle fatigue tests for three full-scale assemblies consisting of steel tubes and bolt-sphere joints, which are widely used in public buildings. Each assembly was tested six times under a varying loading history. The ultralowcycle fatigue performance was investigated considering the joint stiffness and loading history. The deformation patterns, hysteretic characteristics, skeleton curves, bearing-capacity degradation features, cumulative energy dissipation, and cumulative damage index of the assembly were obtained and analysed. The results show that the joint stiffness and loading system have a significant effect on the ultralow-cycle fatigue performance of the assembly. Based on these results, an equation that describes the relationship between the cumulative damage index and the bearing degradation of the assembly for an ultralow-cycle fatigue test was derived.

\section{Introduction}

In the event of severe earthquakes, large deformations and high-stress fatigue damage occur in space grid structures owing to the development of plasticity and the accumulation of damage. This has a significant impact on the structural failure characteristics and bearing limit. Ultralow-cycle fatigue failure occurs when the fatigue life of a structure is less than 100 cycles. In summarising the seismic damage of largespan spatial grid structures since 1985 [1-4] such as the Northridge earthquake in 1994 [5] and the Kobe earthquake in 1995 [6], as shown in Figure 1, the members and joints of spatial grid structures repeatedly experienced plastic deformation and multiple buckling. Moreover, the cumulative damage caused their stiffness to deteriorate and then be pulled or broken. The failure mode has the characteristics of ultralow-cycle fatigue damage. Therefore, research on the ultralow-cycle fatigue performance of spatial grid structures is critical.

Numerous experimental studies and numerical simulations have been conducted on the ultralow-cycle fatigue properties of structural steel $[7,8]$, beam-column joints in steel frame structures [9], and steel members [10]. However, existing research on the ultralow-cycle fatigue performance of space grid structures is limited. Gui-bo et al. [11, 12] conducted an experimental study on the spatial hysteresis performance of circular steel tubes and developed a material constitutive model that considered damage accumulation. The researchers applied the material damage model to a single-layer spherical reticulated shell. It was determined that the cumulative damage had an important effect on the ultimate load of the structure [13]. Goggins et al. [14] studied the hysteretic behaviour of rectangular and square hollowsteel members via experiments and discovered that the slenderness ratio of the members had a significant effect on their tensile and compressive strength, postbuckling bearing capacity, ductility, and energy dissipation capacity.

Salawdeh and Goggins [15] established damage models of rectangular and square hollow-steel members and verified them via experiments. Fan et al. [16] conducted experimental research on the mechanical properties of bolt-ball joints. The results showed that these joints have good bending stiffness, but the stiffness of the joints is usually neglected in the space grid structure design, which is regarded as the ideal articulated joint. Chenaghlou and Nooshin [17] further studied the mechanical properties of 


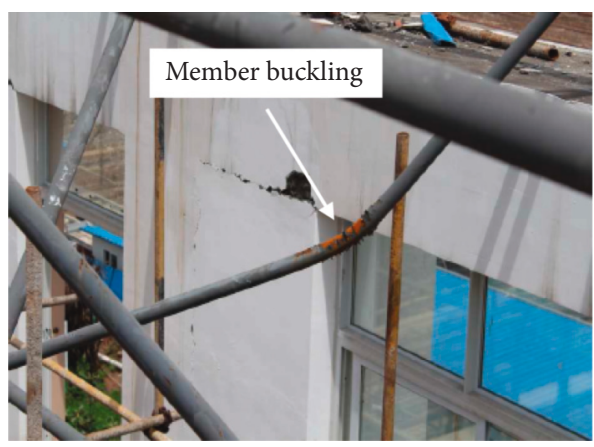

(a)

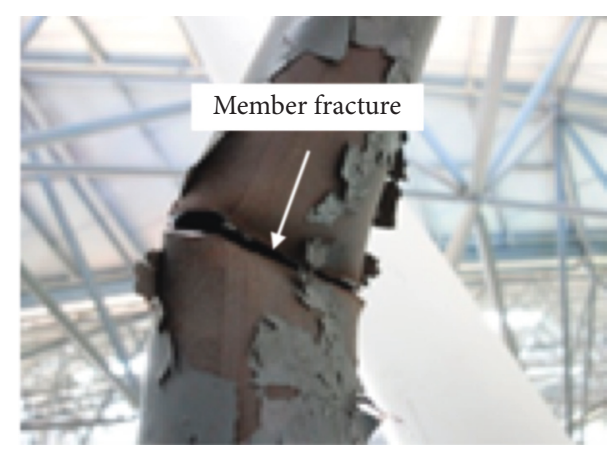

(b)

FIgURe 1: Destruction of spatial grid structure under severe earthquake.

bolt-ball joints, but their research focused on the unidirectional mechanical properties of the bolt-ball joints, which is inconsistent with the actual force of the grid structure during severe earthquakes.

Most of the aforementioned research results are related to the hysteretic behaviour of members and the monotonic mechanical behaviour of bolt-sphere joints. However, under severe earthquakes, the bolt-sphere joints and the members in the spatial grid structure are in a cyclic loading state. Therefore, the mechanical properties of the rods, including the effect of the joint stiffness under cyclic loading, should be further investigated. This paper summarises the damage mode of large-span grid structures under severe earthquakes. Full-scale composite specimens of a bolt-sphere joint and rod were designed, and axial cyclic loads were applied. By changing the high-strength bolts at the end of the rod and adopting different loading systems, the effects of joint stiffness at the end of rod and loading system on the hysteretic behaviour and bearing-capacity degradation of the specimens were studied. The relationship between the bearing-capacity degradation and the damage was established. This provides a reference for evaluating the ultralowcycle fatigue performance of spatial grid structures and serves as a basis for the design of spatial grid structures for severe earthquakes.

\section{Test Program}

2.1. Specimen. An assembly member consisting of a boltsphere joint and a rod is widely used. In this study, the specimen consisted of two bolt-spheres, two high-strength bolts, two sleeves, two dowel pins, two end cones, and a steel tube. The end cones with holes were welded at both ends of the steel tube to form a rod. A high-strength bolt placed in the steel tube was screwed into the bolt-sphere through the hole in the end cone to connect this component to the rod, as shown in Figure 2. A tensile force was transmitted via the contact surface between the bolt and the end cone and by the engagement of the threads between the bolt and bolt-sphere.

A compressive force was transmitted to the bolt ball through the contact surface between the sleeve and the end cone. The material property index of each part is shown in Table 1, in which $E$ denotes Young's modulus of elasticity, $f_{y}$

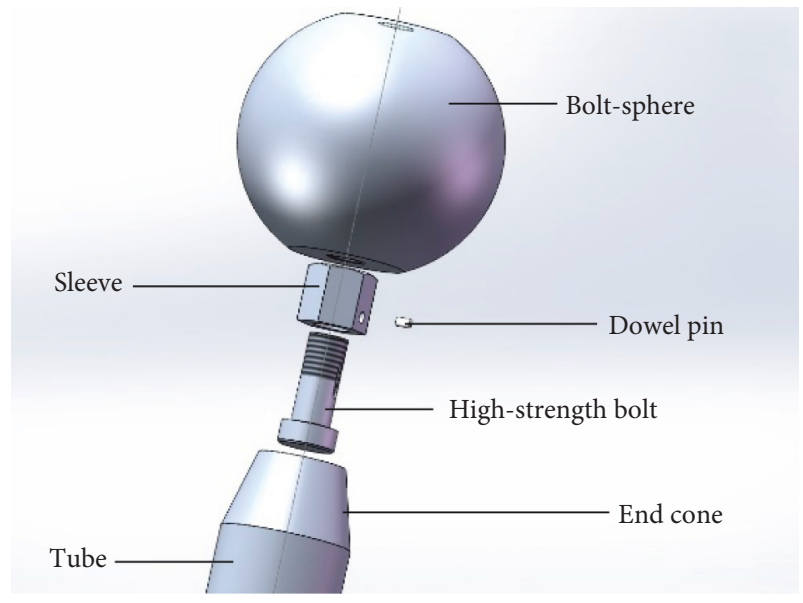

Figure 2: Details of a bolt-sphere joint.

TABLE 1: Material properties of each part.

\begin{tabular}{lcccc}
\hline Part & $f_{y}(\mathrm{MPa})$ & $f_{u}(\mathrm{MPa})$ & $E(\mathrm{MPa})$ & $v$ \\
\hline Bolt-sphere & 365 & 600 & $2.0 \times 105$ & 0.25 \\
High-strength bolt & 900 & 1000 & $2.06 \times 105$ & 0.29 \\
\hline Steel tube & 301 & 417 & $1.97 \times 105$ & 0.27 \\
Sleeve dowel pin end cone & 254 & 470 & $2.06 \times 105$ & 0.29 \\
\hline
\end{tabular}

denotes the steel yield strength, $f_{u}$ denotes the steel ultimate tensile strength, and $v$ denotes the steel Poisson's ratio.

2.2. Specimen and Instrumentation. Fifty-four specimens in three groups (M24, M27, and M30) were tested for different loading systems. The configurations of the specimens are shown in Figure 3, and the corresponding parameters of the specimens are listed in Table 2. The diameter of the highstrength bolt was changed in the configuration parameters of the specimens. The length of the specimen after assembly was $2200 \mathrm{~mm}$.

To simulate the real stress condition of the spatial grid structure, cyclic loading of the specimens was conducted with different systems using the test setup shown in Figure 4. This setup mainly consisted of a reaction frame, actuator, three directional constraints, and a bottom anchoring 


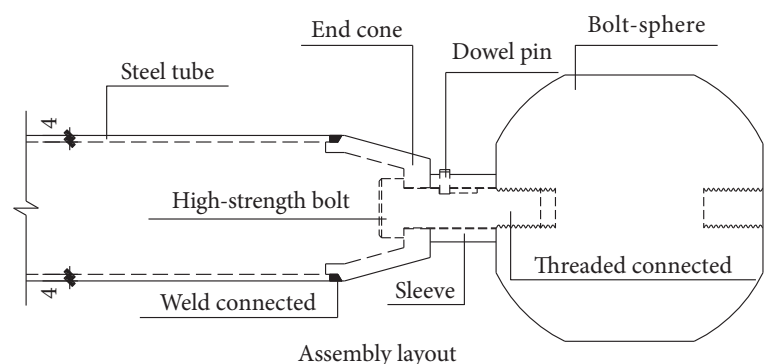

Assembly layout
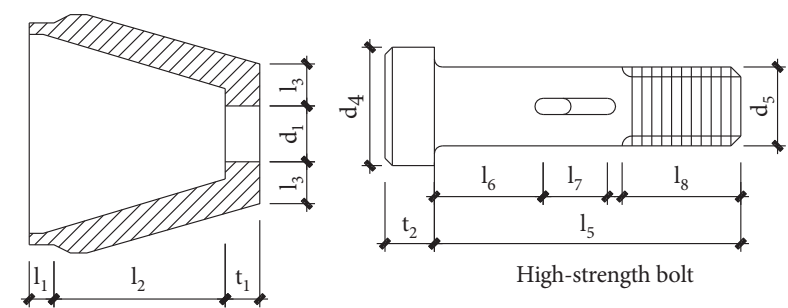

End cone
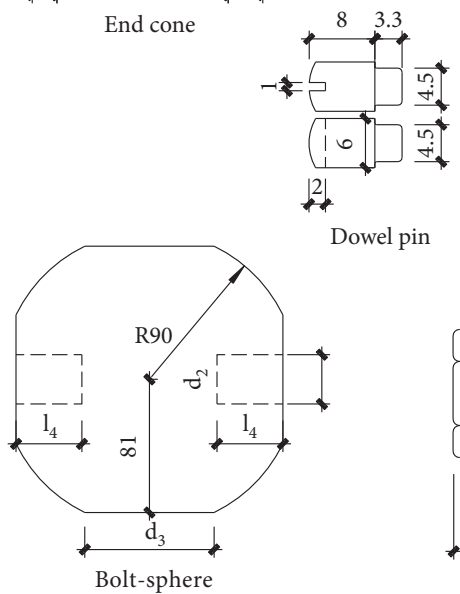

Dowel pin

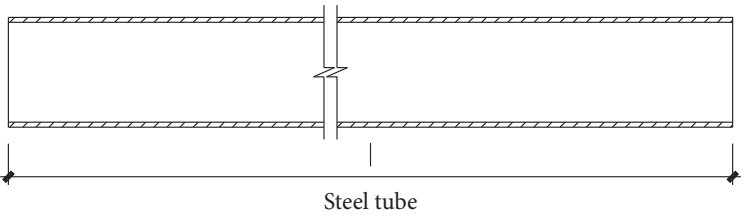

Figure 3: General test details.

TABLE 2: Geometrical parameters of specimen corresponding to Figure 2.

\begin{tabular}{|c|c|c|c|c|c|c|c|c|c|c|c|c|c|c|c|c|c|c|c|c|c|c|c|}
\hline \multirow[t]{2}{*}{ Group ID } & \multirow[t]{2}{*}{ Quantity } & \multicolumn{5}{|c|}{ End cone (mm) } & \multicolumn{3}{|c|}{$\begin{array}{l}\text { Bolt-sphere } \\
\quad(\mathrm{mm})\end{array}$} & \multicolumn{7}{|c|}{ High-strength bolt (mm) } & \multicolumn{5}{|c|}{ Sleeve $(\mathrm{mm})$} & \multicolumn{2}{|c|}{$\begin{array}{l}\text { Steel tube } \\
\quad(\mathrm{mm})\end{array}$} \\
\hline & & $l_{1}$ & $l_{2}$ & $l_{3}$ & $t_{1}$ & $d_{1}$ & $l_{4}$ & $d_{2}$ & $d_{3}$ & $l_{5}$ & $l_{6}$ & $l_{7}$ & $l_{8}$ & $d_{4}$ & $d_{5}$ & $t_{2}$ & $l_{9}$ & $l_{10}$ & $d_{6}$ & $d_{7}$ & $R$ & $l$ & $D$ \\
\hline & & 6 & & & & & & & & & & & & & & & & & & & & & 88.5 \\
\hline $0<1$ & & 6 & 44 & 2 & & 2 & 33 & & & & & & & & & & & & & & & & 88.5 \\
\hline S30 & 54 & 6 & 44 & 19 & 20 & 31 & 35 & 30 & 78.5 & 98 & 28 & 24 & 37 & 46 & 30 & 18.7 & 10 & 45 & 55.6 & 50 & 15.5 & 1816 & 88.5 \\
\hline
\end{tabular}

device. The test was conducted using a $1000 \mathrm{kN}$ hydraulic servo actuator matched with an all-digital hydraulic servo system produced by FCS (Beijing Fluid Control System) Corp. The system can be loaded with six channels in coordination, and the static precision of the load and displacement reached 1\% Full Scale (FS).

The upper bolt-sphere of the specimen was connected to the load transfer device via the upper base, and the load transfer device was connected to the actuator via four countersunk bolts, as shown in Figure 5.

To ensure an axial load, three directional constraints were installed on the load transfer device under the actuator, as shown in Figures 5 and 6 . The three directional constraints were mainly composed of three adjustable-length circular steel tubes, vertical sliding grooves fixed on the reaction frame by the high-strength bolts, and hooks welded 


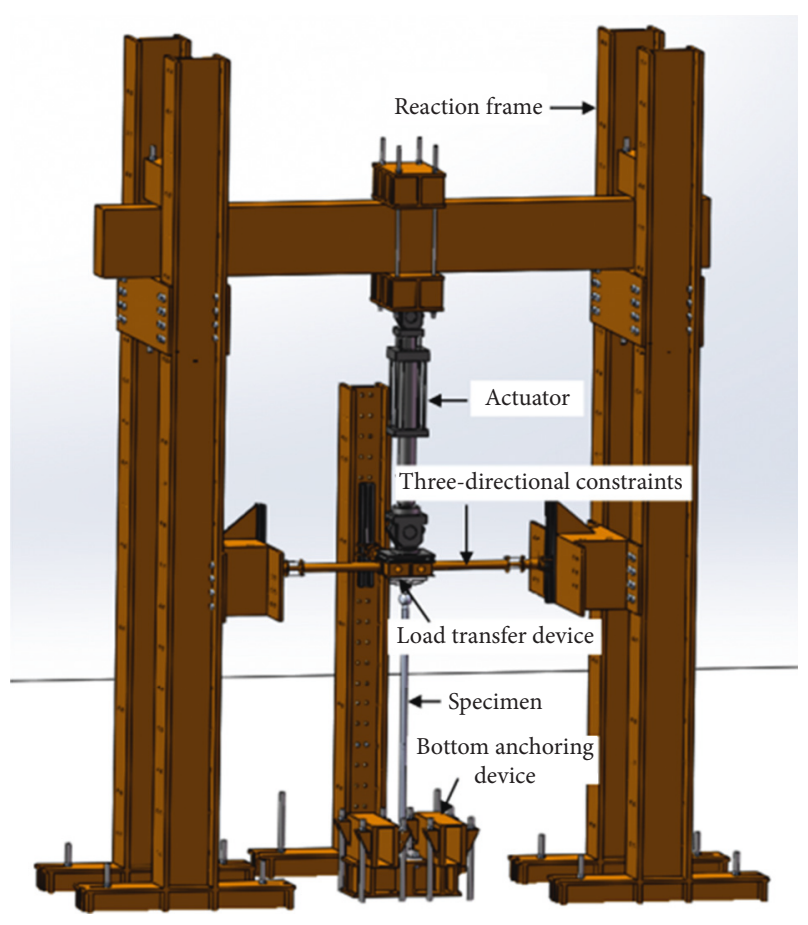

Figure 4: Test setup.

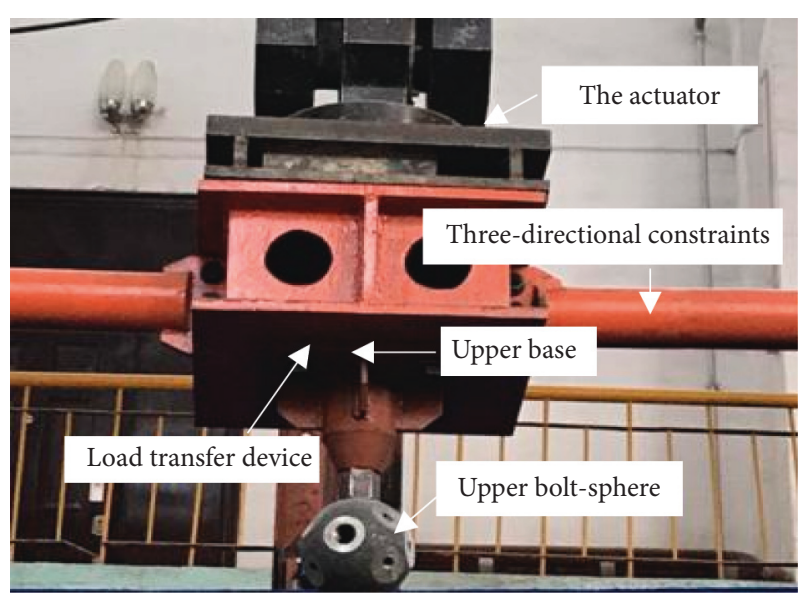

Figure 5: Load transfer device details.

to the endplate of the circular steel tubes. The latter, with an adjustable length, included a circular steel tube, two ring flanges, and three variable-length screws.

One end of the circular steel tube was welded to the ring flange, and the other end was connected to a load transfer device via three high-strength bolts, as shown in Figures 5 and 6 . The length of the steel tube was changed by adjusting the position of the nuts on the three screws on the ring flanges. During loading, the three directional constraints ran up and down the track via the pulleys to ensure axial loading.

As shown in Figure 7, the lower bolt-sphere of the specimen was connected to the steel capping beam via the bottom base, and the steel capping beam was fixed in a groove in the floor of the laboratory via two steel restrained

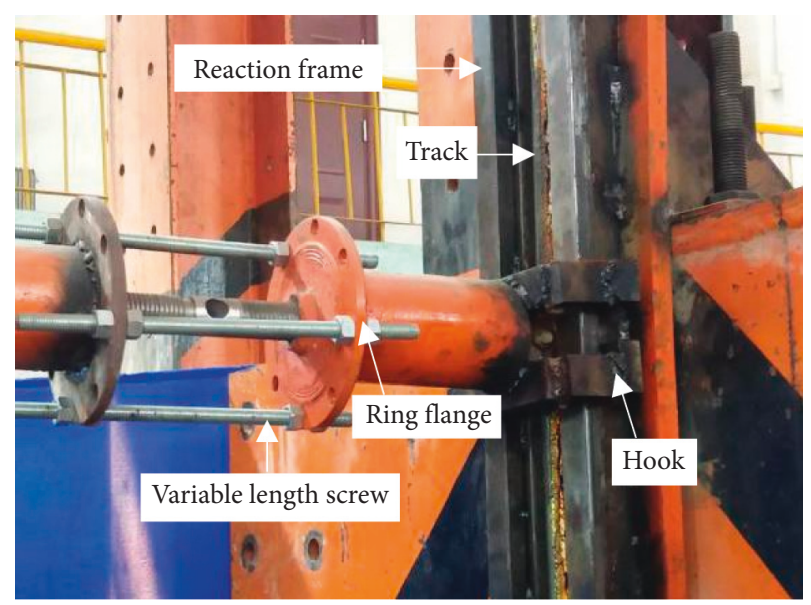

FIGURE 6: Details of three directional constraints.

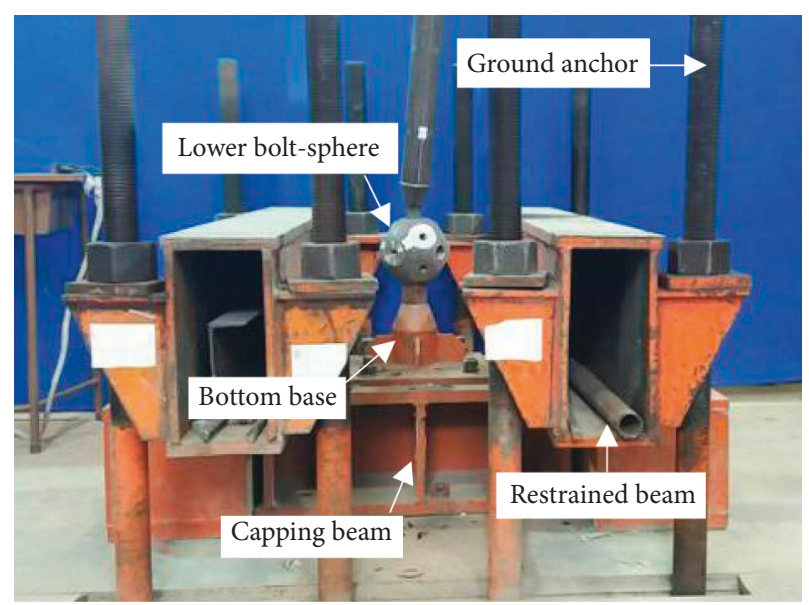

FIGURE 7: Bottom anchoring device.

beams and eight ground anchors to ensure the lower part of the assembled specimen was fixed.

2.3. Data Acquisition System. The applied axial load was measured using the force transducer of an electrohydraulic servo actuator.

During testing, the specimen underwent large spatial deformation with a random deformation direction. It is difficult to comprehensively measure and study the spatial deformation of specimens using conventional instruments such as a dial indicator and a displacement sensor, especially in an area without monitoring points. Therefore, in this test, an Artec EVA 3D scanning system (made in Russia) was adopted to obtain 3D data for the specimens, as shown in Figure 8. The working range of the instrument is $0.4 \mathrm{~m}-1 \mathrm{~m}$, and the data accuracy is $0.1 \mathrm{~mm}$. To obtain the complete deformation of the specimen, the Artec EVA 3D scanner was used to collect a point cloud for the surface of the specimen and $3 \mathrm{D}$ coordinates and surface texture information for the surface points and for reconstruction of the model in the correlation software of the scanner. Using these data, it was 


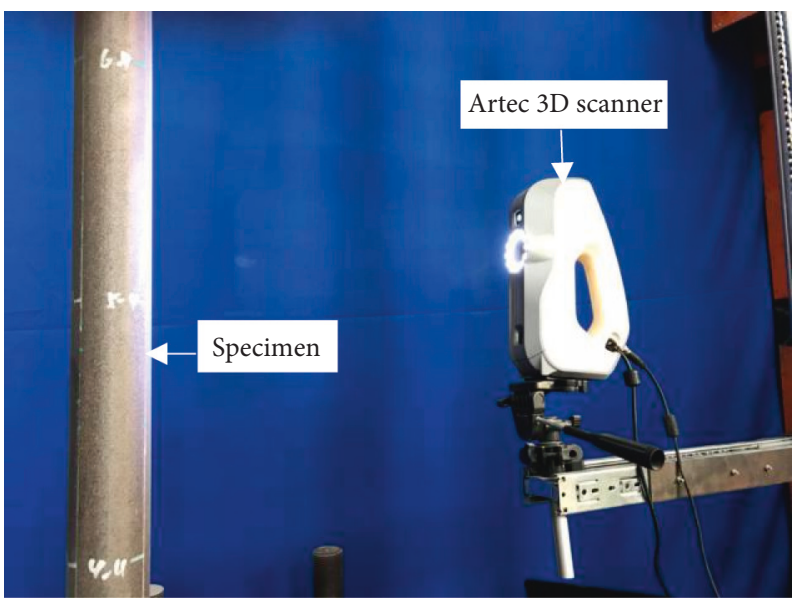

Figure 8: Artec 3D scanner.

possible to obtain a high-precision 3D model of the entire specimen.

The total station was used to measure the coordinates of control points 1-11 in Figure 9 at each load step and to calculate the amount of spatial deformation of the specimen.

2.4. Loading Scheme. To study the ultralow-cycle fatigue performance of the specimens under cyclic loading in detail, six different loading systems were used to load the specimens, as shown in Table 3. The loading systems are shown in Figure 10. A mixed control mode of force and displacement was adopted in the test. Before the yield of the specimen, the load control test was adopted. After the yield of the specimen, a displacement control test was adopted. According to the feedback value of the force and the displacement of the specimen, the tensile yield displacement $\Delta_{\mathrm{t}}=11 \mathrm{~mm}$ and the compressive yield displacement $\Delta_{c}=18 \mathrm{~mm}$ of the specimen were determined. Since there was minimal damage in the elastic stage, the test was performed from the elastoplastic stage until the specimen fractured.

For loading system I, the magnitude of the displacement under tension and the compression increased stepwise. The increment of each stage of the tension displacement load was $20 \%$ of $\Delta_{t}$, that is, $2.2 \mathrm{~mm}$, and that of the compression displacement load was $20 \%$ of $\Delta_{c}$, that is, $3.6 \mathrm{~mm}$. For loading system II, the tensile load remained unchanged at $1.2 \Delta_{\mathrm{t}}$, that is, $13.2 \mathrm{~mm}$, and the compression amplitude increased stepwise. The increment of the displacement load at each stage was $20 \%$ of $\Delta_{c}$, that is, $3.6 \mathrm{~mm}$. For loading system III, the compression load remained unchanged at $1.2 \Delta_{c}$, that is, $21.6 \mathrm{~mm}$, the tensile amplitude increased stepwise, and the increment of the displacement load at each stage was $20 \%$ of $\Delta_{t}$, that is, $2.2 \mathrm{~mm}$. For loading system IV, the tensile displacement amplitude remained unchanged at $1.3 \Delta_{\mathrm{t}}$, that is, $14.3 \mathrm{~mm}$, while the compression displacement amplitude remained unchanged at $1.3 \Delta_{c}$, that is, $23.4 \mathrm{~mm}$. For loading system $\mathrm{V}$, the tensile displacement amplitude remained unchanged at $1.3 \Delta_{\mathrm{t}}$, that is, $14.3 \mathrm{~mm}$, while the compression displacement amplitude remained unchanged at $1.4 \Delta_{c}$, that is, $23.4 \mathrm{~mm}$. For loading system VI, the tensile displacement amplitude remained unchanged at $1.4 \Delta_{t}$, that is, $15.4 \mathrm{~mm}$, while the compression displacement amplitude remained unchanged at $1.4 \Delta_{c}$, that is, $23.4 \mathrm{~mm}$.

\section{Test Results}

3.1. Test Stability Verification. To verify the stability of the test and data acquisition equipment, each test was repeated three times. The stability of the test is illustrated by S24-II-1/ 2/3, S27-III-1/2/3, and S30-I-1/2/3 in Figure 11.

It is evident from Figure 11 (for convenience, the large deformed part prior to failure is hidden) that the three hysteresis curves for each set of tests are basically consistent, indicating that the stability of the test was good and the test results are credible. Given that each test was repeated three times and there were many curves, the average value of the three repeated tests is used in the following analysis.

3.2. Test Process and Failure Mode. The test processes for each specimen were similar. All specimens experienced a relatively stable elastic stage of force and deformation, integral bending deformation, local dents, crack initiation, crack development, specimen cracking, and specimen fracture, as shown in Figure 12. During the test, the hysteretic relationship between the load and the displacement at the bolt-sphere at the end of the rod and plastic deformation crack development, cracking, and fracture of the rod were recorded.

The special moments of all specimens are listed in Table 4. Examining the data in this table except for loading system II, when the same loading system was used in the test, the larger the bolt diameter at both ends of the specimen, the earlier the local dent occurred and the earlier the occurrence of cracking and fracture was. Compared to the special moment of all tests, the bolt diameter at both ends of the specimen increased, and the ultralow-cycle fatigue life of the specimen decreased. This is because the greater the diameter of the bolts at both ends of the specimen, the higher the rotational stiffness of the joints at the ends. This results in a greater bending moment in the middle of the specimen and an earlier occurrence of local depression. 


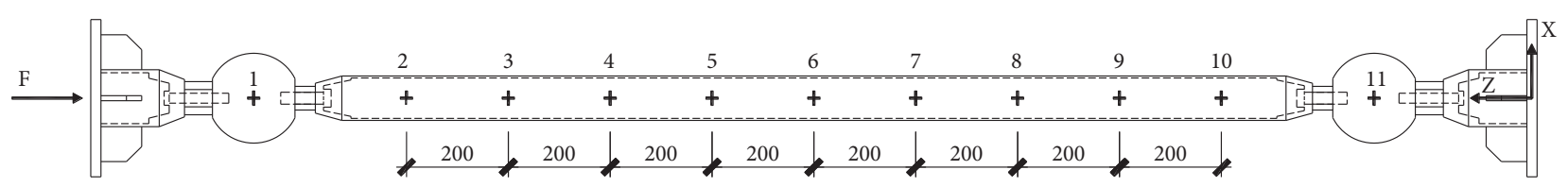

FIgURE 9: Control point distribution.

TABLE 3: Loading systems for specimens.

\begin{tabular}{|c|c|c|}
\hline Group ID & Test ID & Loading system \\
\hline \multirow{6}{*}{ S24 } & S24-I-1/2/3 & I \\
\hline & S24-II-1/2/3 & II \\
\hline & S24-III-1/2/3 & III \\
\hline & S24-IV-1/2/3 & IV \\
\hline & $\mathrm{S} 24-\mathrm{V}-1 / 2 / 3$ & $\mathrm{~V}$ \\
\hline & S24-VI-1/2/3 & VII \\
\hline \multirow{6}{*}{ S27 } & S27-I-1/2/3 & I \\
\hline & S27-II-1/2/3 & II \\
\hline & S27-III- $1 / 2 / 3$ & III \\
\hline & S27-IV-1/2/3 & IV \\
\hline & $\mathrm{S} 27-\mathrm{V}-1 / 2 / 3$ & $\mathrm{~V}$ \\
\hline & S27-VI-1/2/3 & VII \\
\hline \multirow{6}{*}{ S30 } & $\mathrm{S} 30-\mathrm{I}-1 / 2 / 3$ & I \\
\hline & S30-II-1/2/3 & II \\
\hline & S30-III-1/2/3 & III \\
\hline & S30-IV-1/2/3 & IV \\
\hline & $\mathrm{S} 30-\mathrm{V}-1 / 2 / 3$ & $\mathrm{~V}$ \\
\hline & S30-VI-1/2/3 & VII \\
\hline
\end{tabular}

Note. The last part of the test ID is the number of repetitions of the test.

It is evident that the joint stiffness has a significant effect on the ultralow-cycle fatigue life of specimens. Compared to the fatigue life of the specimens for different loading systems, the fatigue life of the specimens under loading system II was approximately twice that of loading system I. Moreover, the fatigue life of the specimens under loading system III was approximately 1.6 times that of loading system I. Therefore, it is evident that the tensile force had a greater effect on the ultralow-cycle fatigue life of the specimens than the compressive force.

3.3. Hysteretic Curve. The load-displacement hysteretic curves of the specimens are shown in Figure 13. Given that the performance of the specimen at the elastoplastic stage was studied, the entire bending deformation of the specimen occurred at the first time of compression and entered the elastoplastic state. At the beginning of the test, the hysteresis loop of the specimen already had a certain area. However, at this time, the plastic deformation of the specimen was small, and so the area surrounded by the hysteresis loop was not large. As the displacement amplitude increased stepwise, the residual deformation increased gradually when the load was unloaded to zero, and the area of the hysteresis loop increased gradually and tended to be full. As shown in Figure 13, the hysteretic curves of all specimens were still quite full after the ultimate compressive capacity was reached, and there was no distinct narrowing phenomenon. This indicated that the energy dissipation capacity of the specimens was good.
Figures 13(b)-13(f) show that when the displacement amplitude remained unchanged, the maximum load per cycle gradually decreased with an increase in the number of cycles. This indicated that the bearing capacity of the specimens gradually decreased under cyclic loads, and the maximum load per cycle decreased significantly after the local dent of the specimens. This is owing to a local dent in the middle of the specimen when local buckling occurs. The material in the local dent is in a complex stress state, alternating between tension and compression under reciprocating loads, which results in damage inside the material. With an increase in the number of cycles, the damage accumulates gradually, and the bearing capacity of the specimen gradually decreases.

3.4. Skeleton Curve. The skeleton curve is an envelope connecting the peak points of the first cycle of the hysteretic curve at all levels of load. Figures 14(a)-14(c) show the skeleton curves of all specimens. The corresponding feature values of the skeleton curves are listed in Table 5. Under the same loading system, when the displacement amplitudes were the same, the bolt diameter at the end of the specimen increased, and the bearing capacity of the test piece also increased.

As shown in Figure 14, the skeleton curves had an obvious feature, in that when the tension and compression state of the specimens changed, a part of the curves passed through the zero point, while another part did not. When cyclic loading started owing to the compression force, the skeleton curves of the specimens did not pass through the zero point. This is owing to the overall bending deformation of the specimen during the first compression. At this time, the specimen had a certain plastic deformation, and the residual deformation when unloading was zero caused the skeleton curve of the specimen to no longer pass through the zero point. It is evident that the initial state of the specimens under cyclic loading affected their skeleton curves.

\subsection{Bearing-Capacity Degradation and Cumulative Energy Dissipation}

3.5.1. Degradation of Bearing Capacity. Under cyclic loading, the accumulation of damage leads to a gradual degradation in the load-bearing capacity of the specimens. The ratio of the residual carrying capacity per cycle $F_{i}$ to the initial carrying capacity $F_{0}$ was used to represent the degradation of the specimens, as shown in the following equation:

$$
\lambda_{i}=\frac{F_{i}}{F_{0}}
$$




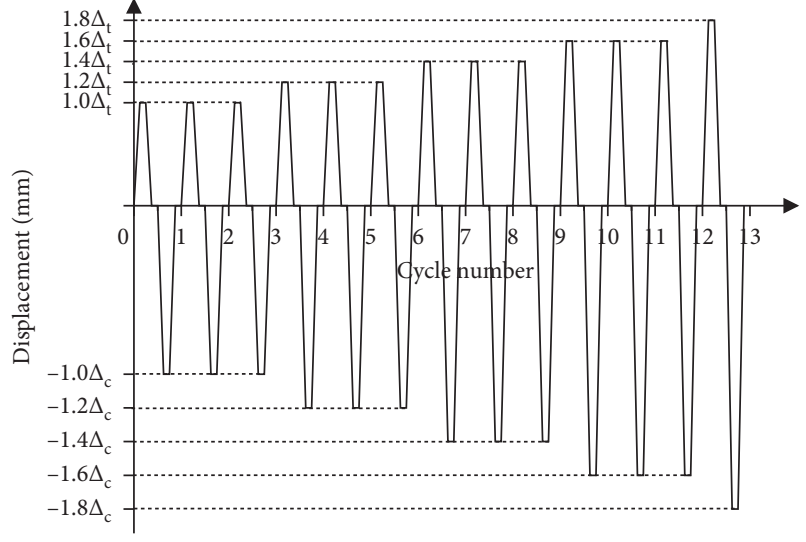

(a)

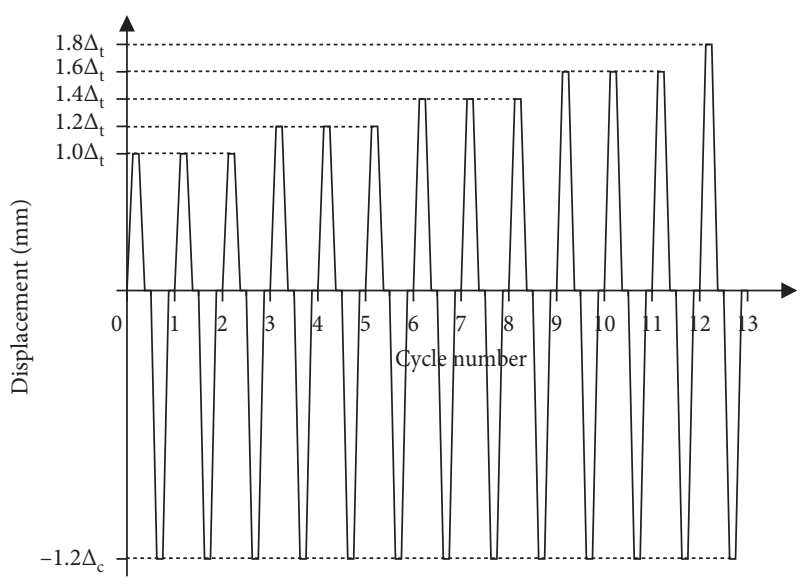

(c)

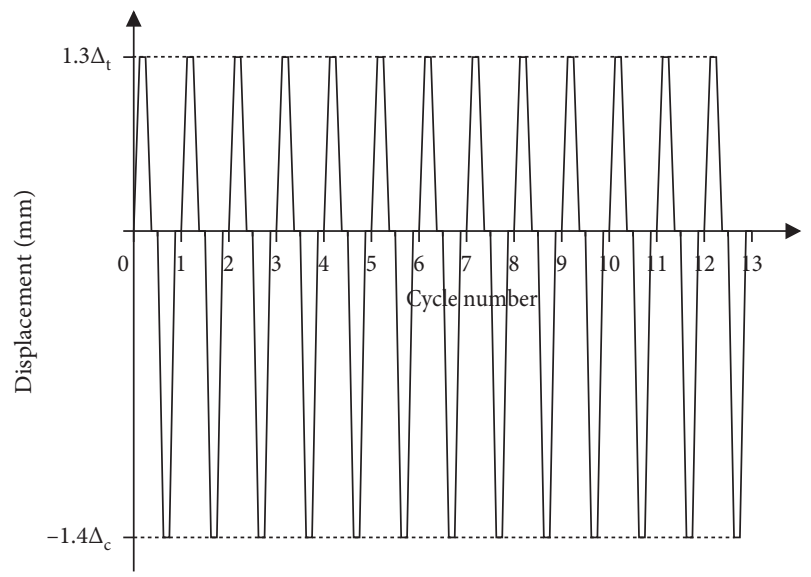

(e)

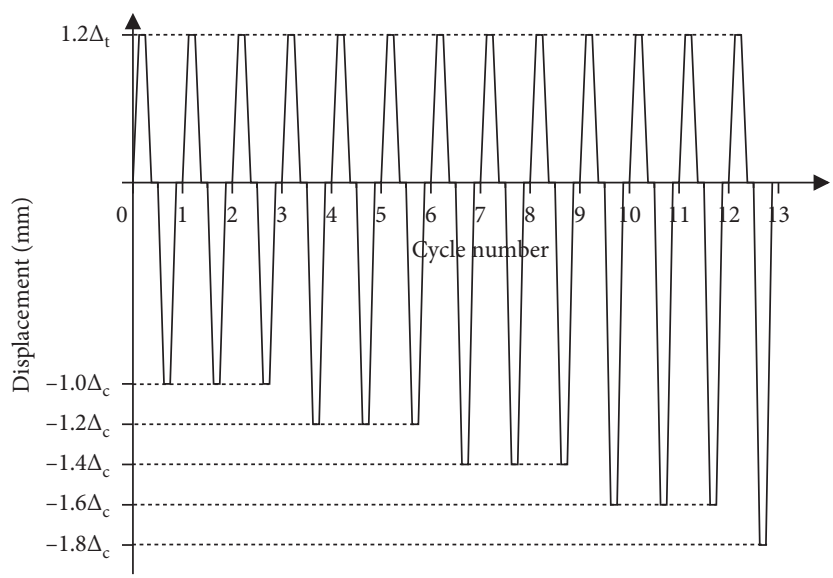

(b)

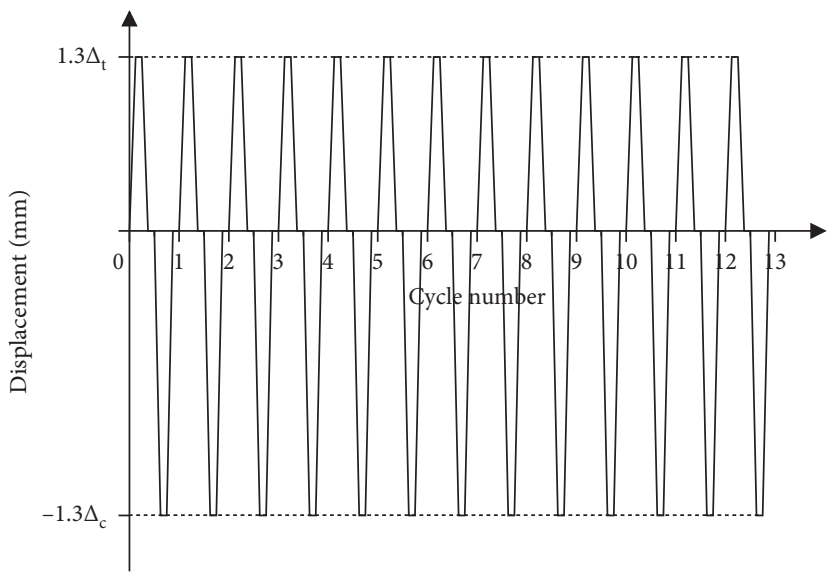

(d)

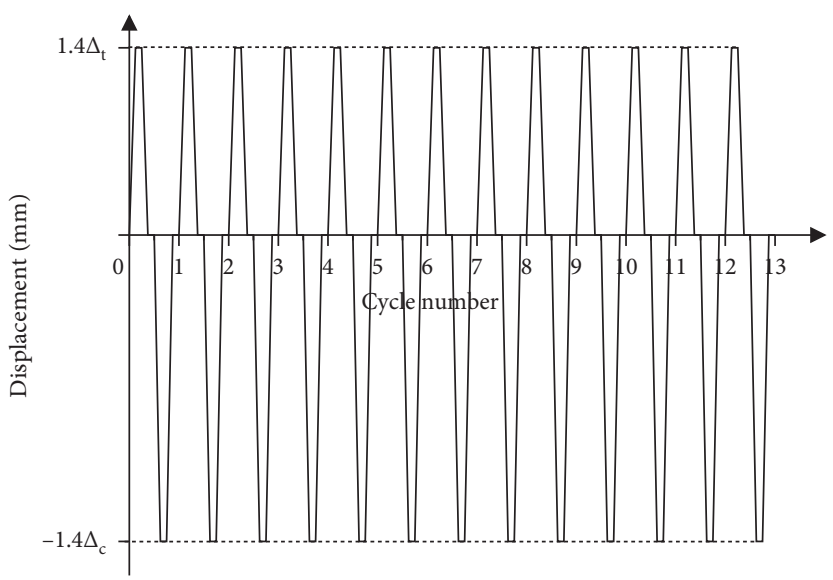

(f)

FIGURE 10: Loading systems: (a) loading system I, (b) loading system II, (c) loading system III, (d) loading system IV, (e) loading system V, and (f) loading system VI.

where $F_{i}$ is the bearing capacity of the specimen during each cycle loading and $F_{0}$ is the initial bearing capacity of the specimen.

The load-bearing degradation curves obtained from the tests are shown in Figure 15. In the legend, $T$ indicates that the specimen is under tension, and $P$ indicates that the specimen is under pressure. As shown in Figure 15, the degradation rate of the tensile-bearing capacity of all specimens was lower than that of the compressive bearing capacity.

Comparing Figures 15(a) and 15(b), the characteristics of the degradation curves of bearing capacity under compression exhibited great differences before cracking, although the loading system under compression was the same. 


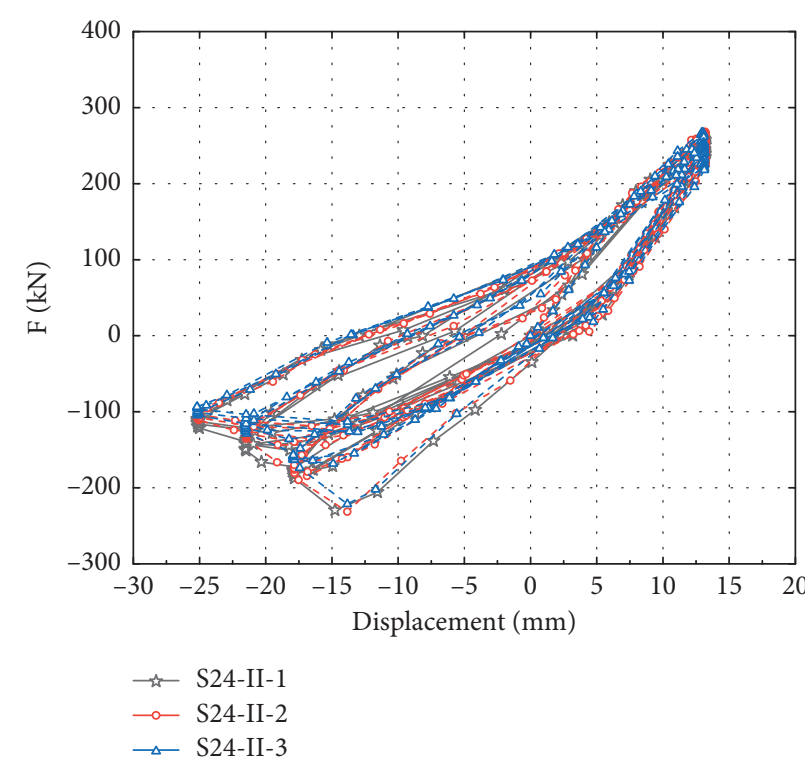

(a)

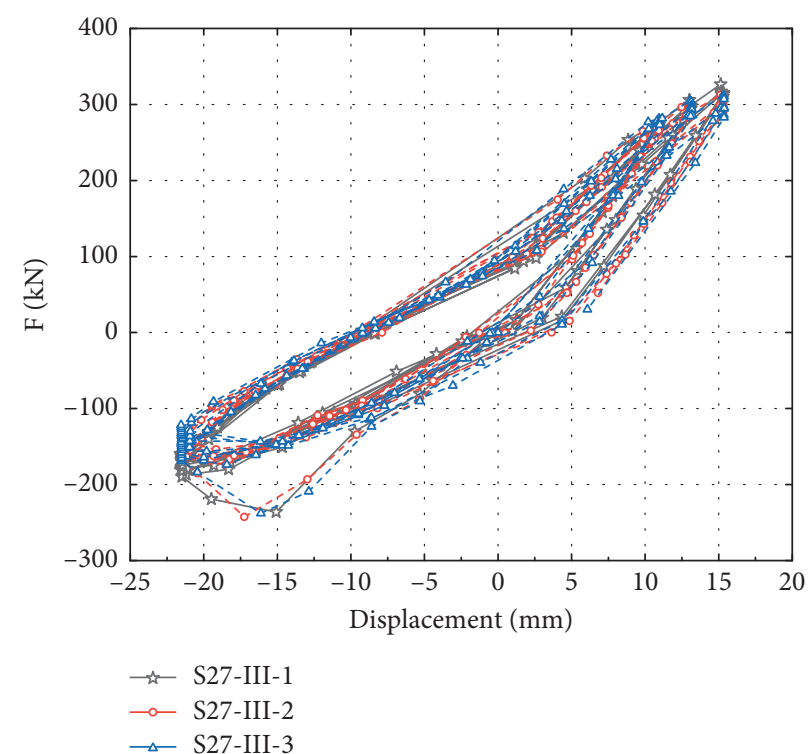

(b)

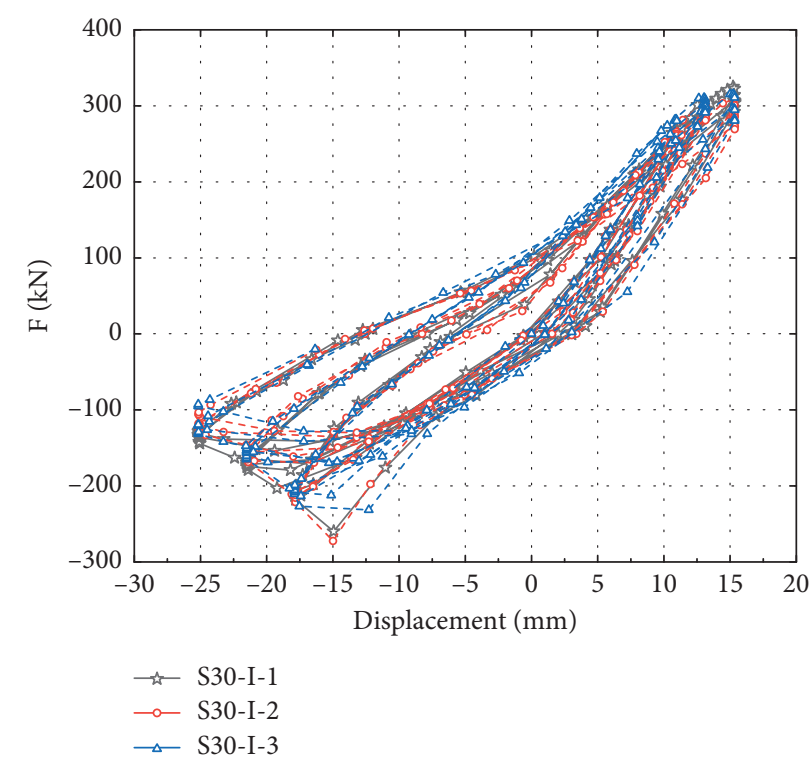

(c)

FIgURE 11: Hysteretic curve comparison. (a) S24-II. (b) S27-II. (c) S30-I.

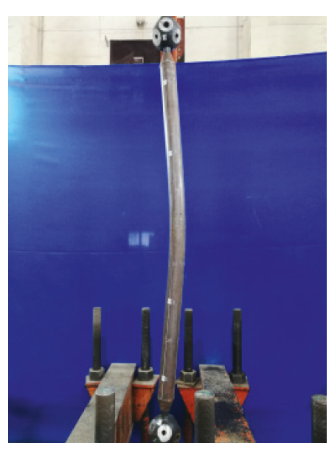

(a)

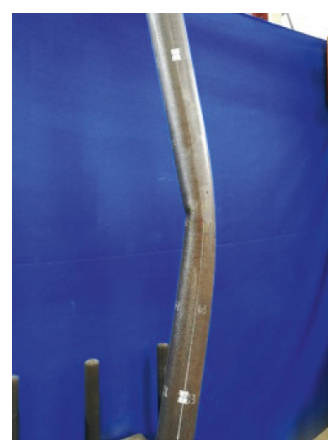

(b)

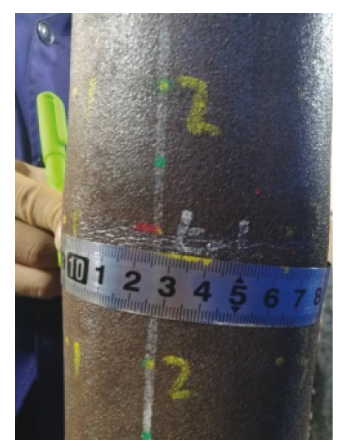

(c)

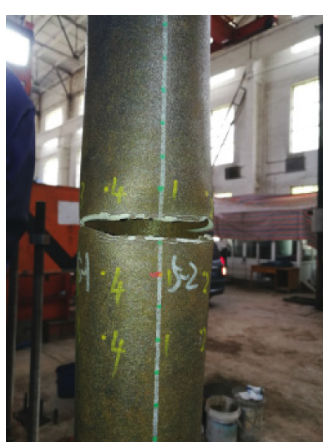

(d)

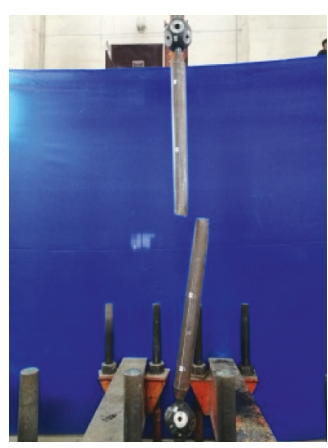

(e)

Figure 12: Characteristic points of test process. (a) Integral bending deformation, (b) local dent, (c) crack initiation, (d) specimen cracking, and (e) specimen fracture. 
TABLE 4: Characteristic points of test process.

\begin{tabular}{|c|c|c|c|c|c|}
\hline Test ID & Loading system & Local dent (cycle time) & Crack initiation (cycle time) & $\begin{array}{c}\text { Specimen cracking } \\
\text { (cycle time) }\end{array}$ & $\begin{array}{l}\text { Specimen fracture } \\
\text { (cycle time) }\end{array}$ \\
\hline S24-I & I & 13 & 13 & 14 & 15 \\
\hline S27-I & I & 12 & 13 & 13 & 14 \\
\hline S30-I & I & 9 & 11 & 12 & 12.5 \\
\hline S24-II & II & 10 & 13 & 15 & 31 \\
\hline S27-II & II & 10 & 13 & 14 & 28.5 \\
\hline S30-II & II & 12 & 14 & 15 & 24.5 \\
\hline S24-III & III & 22 & 23 & 25 & 25 \\
\hline S27-III & III & 20 & 21 & 22 & 22 \\
\hline S30-III & III & 16 & 17 & 17 & 19 \\
\hline S24-IV & IV & 10 & 13 & 15 & 72 \\
\hline S27-IV & IV & 6 & 8 & 10 & 19.5 \\
\hline S30-IV & IV & 6 & 7 & 8 & 19.5 \\
\hline S24-V & $\mathrm{V}$ & 6 & 9 & 12 & 57 \\
\hline S27-V & $\mathrm{V}$ & 5 & 7 & 9 & 19 \\
\hline $\mathrm{S} 30-\mathrm{V}$ & $\mathrm{V}$ & 4 & 6 & 8 & 16.5 \\
\hline S24-VI & VI & 6 & 7 & 9 & 50 \\
\hline S27-VI & VI & 5 & 6 & 7 & 12 \\
\hline S30-VI & VI & 4 & 5 & 7 & 8 \\
\hline
\end{tabular}

Therefore, the tension state of the specimens affected the degradation of the compressive bearing capacity of the specimens. Comparing Figures 15(a) and 15(c), the degradation curves of the tensile-bearing capacity of the specimens had similar characteristics, although the loading system under compression was different. This indicates that the compression state of the specimens had minimal effect on the degradation of the tensile-bearing capacity of the specimens.

As shown in Figure 15, the residual capacity of the S30 specimens was the highest under variable-amplitude loading systems (I-III). When local dents occurred in the specimen, the residual tensile capacity of S30 was approximately 5\%$10 \%$ higher than that of the other two specimens, and the compressive residual bearing capacity was approximately $10 \%-15 \%$ higher than that of the other two specimens. In the constant-amplitude loading systems (IV-VI), the residual tensile capacity of S30 was approximately $0-7 \%$ higher than that of the other two specimens, and the compressive residual bearing capacity was approximately $0-15 \%$ higher than that of the other two specimens.

As a result, the loading system and the stiffness of the bolt-sphere joints at both ends of the specimens had a significant effect on the degradation of the bearing capacity of the specimens.

3.5.2. Energy Dissipation Capacity. The cumulative dissipated energy per cycle was used to measure the energy dissipation capacity of the specimens. The higher the former, the better the energy dissipation capacity of the specimen. The energy dissipated per cycle for the specimen was calculated from the area enclosed by the hysteresis curve per cycle, and the cumulative dissipated energy of each specimen varied with the number of cycles, as shown in Figure 16.
Comparing the curves in Figure 16, the energy accumulation trend of the variable-amplitude loading and the constant-amplitude loading was different. The cumulative dissipation energy of the specimens increased nonlinearly when variable-amplitude loading was used. Besides, the cumulative dissipation energy of the specimens increased linearly when constant-amplitude loading was used.

In the initial stage of loading, the energy accumulation rate for constant-amplitude loading was greater than that for variable-amplitude loading. However, the cumulative dissipation energy of the variable-amplitude loading was higher than the cumulative dissipation energy for normal-amplitude loading when the specimen was broken.

Comparing the curves in Figure 16, S24 dissipates less energy than the other two specimens. As such, the loading history and stiffness of the bolt-sphere joints at both ends of the specimens had significant effects on the cumulative energy dissipation capacity.

3.6. Cumulative Damage Index. To consider the effects of variable-amplitude loading and constant-amplitude loading on the damage evolution of the assembly, a damage model based on energy dissipation proposed by Xu et al. [18] was used in this investigation.

$$
D=\frac{\int_{0}^{t} M(t) \mathrm{d} \theta}{W_{E}}
$$

where $D$ is the damage index of the steel frame joints, $M$ is the maximum moment of a member section at moment $t$, $\int_{0}^{t} M(t) \mathrm{d} \theta$ is the cumulative energy dissipation of the component from moment $t$, and $W_{E}$ is the total energy dissipation of the component. 


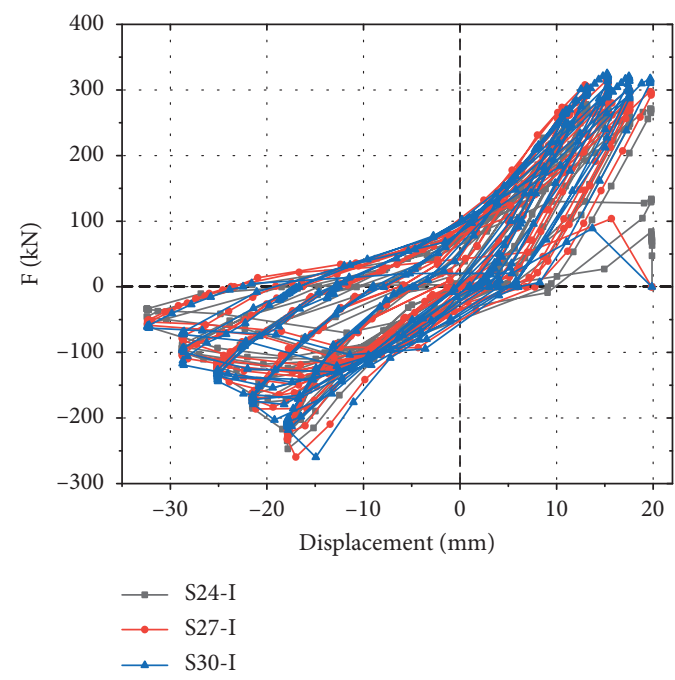

(a)

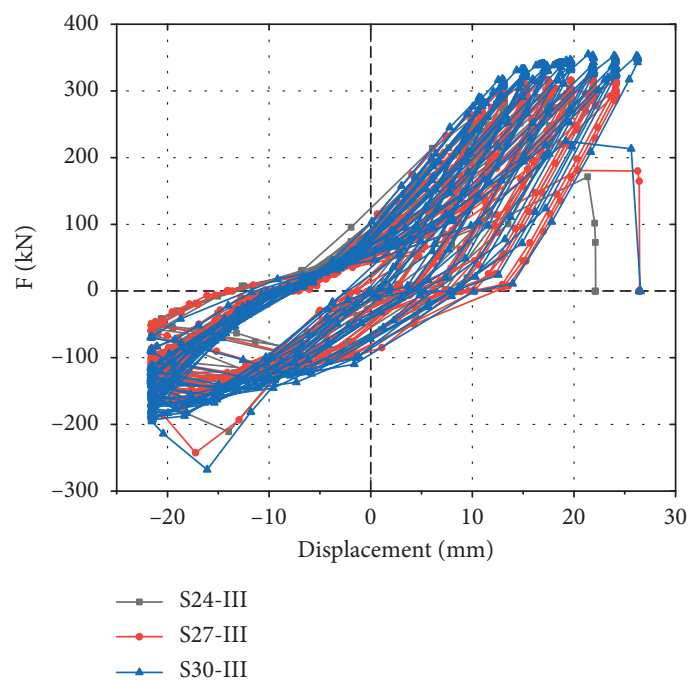

(c)

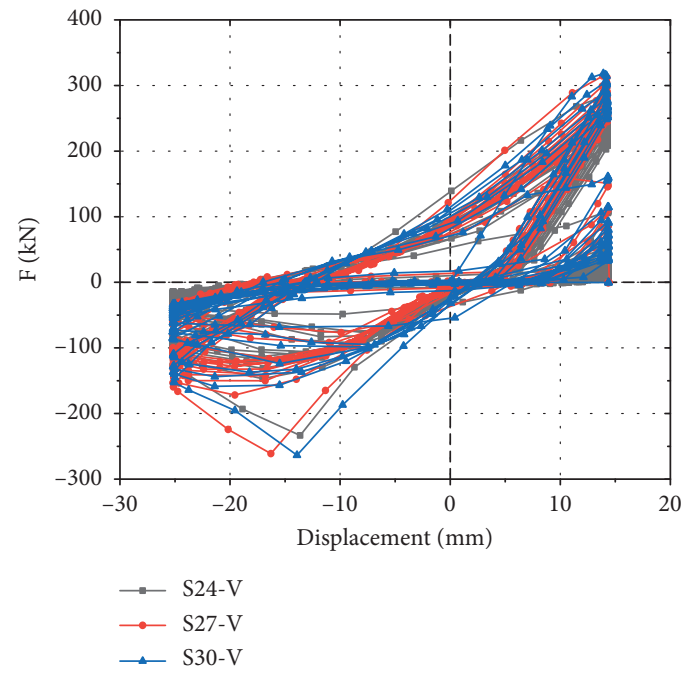

(e)

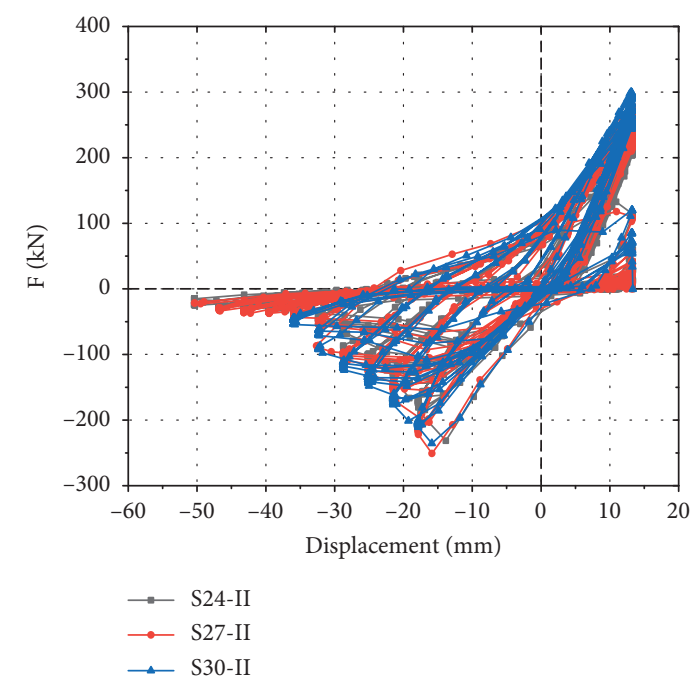

(b)

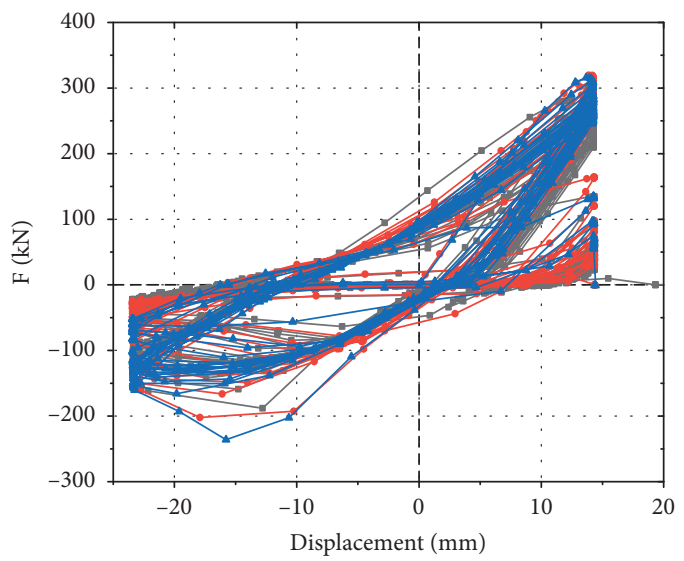

$\rightarrow$ S24-IV

$\rightarrow$ S27-IV

$\rightarrow$ S30-IV

(d)

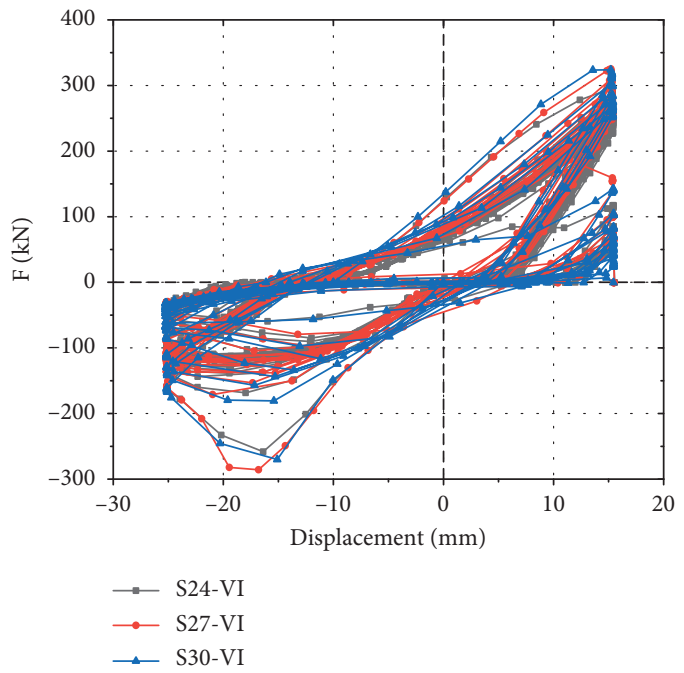

(f)

FIGURE 13: Comparison of load-displacement hysteretic curves at ends of composite specimens. (a) Hysteretic curve under system. (b) Hysteretic curve under system II. (c) Hysteretic curve under system III. (d) Hysteretic curve under system IV. (e) Hysteretic curve under system V. (f) Hysteretic curve under system VI. 


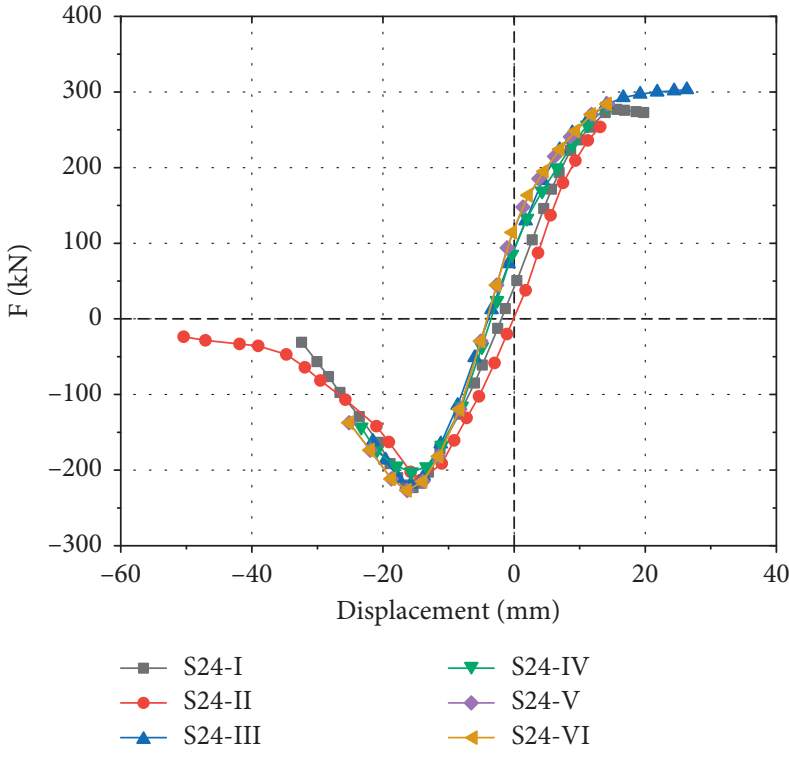

(a)

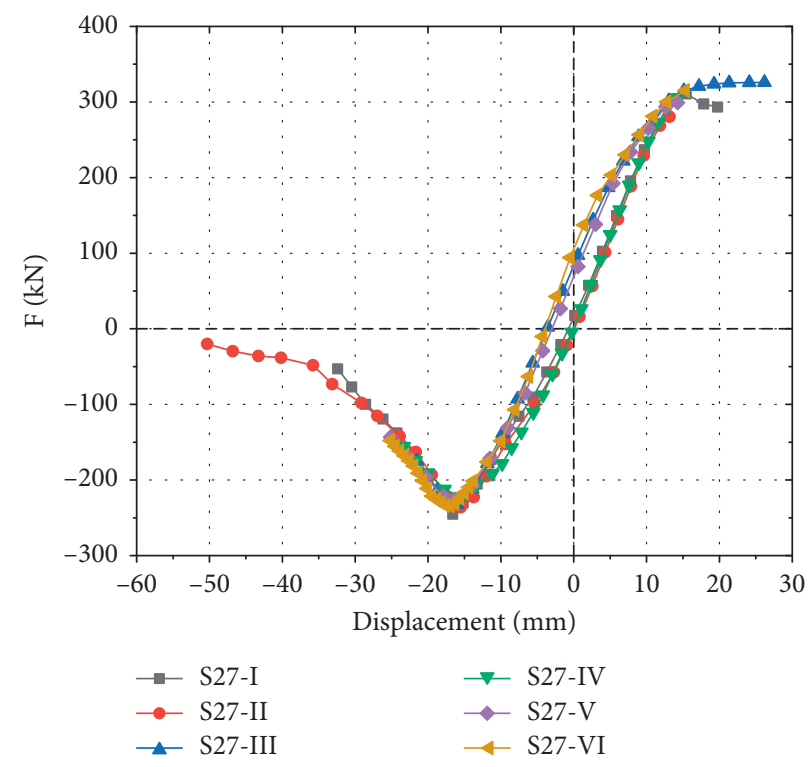

(b)

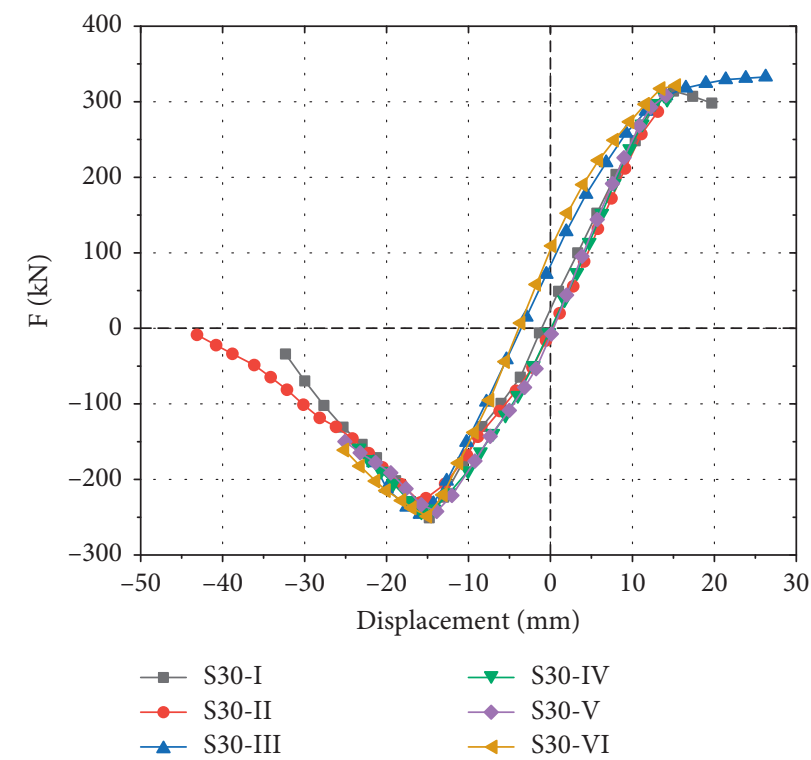

(c)

FIGURE 14: Comparison of skeleton curves. (a) Skeleton curves of S24. (b) Skeleton curves of S27. (c) Skeleton curves of S30.

3.6.1. Effect of Joint Stiffness on Damage Evolution. The damage index of each specimen was calculated according to formula (2), as shown in Figure 17.

As shown in this figure, the damage index of the specimens followed a certain distribution law. Under different loading systems (Figures 17(a)-17(c)), the damage index curves of the specimens developed differently, but they all showed similar three-stage development. The damage index of all specimens increased nonlinearly when damage index $D$ was between 0 and 0.3 . This index also increased linearly when the damage index $D$ was between 0.3 and 0.7 , and the damage rate of the specimens decreased slightly. However, the damage index increased nonlinearly when the damage index $D$ was between 0.8 and 1.0.
Under the constant-amplitude loading systems (Figures 17(d)-17(f)), the cumulative damage index of all specimens increased linearly before cracking. For the three constant-amplitude loading systems, the slope of the curves in Figure 17(f) was the largest, and the accumulation of damage was the fastest. As shown in Figures $17(\mathrm{~d})-17(\mathrm{f})$, the cumulative rate of damage of the S30 specimens was the largest; the damage development was the fastest, and the first cracking failure occurred. When the load was cycled for the 6 th time under system $\mathrm{VI}$, the damage index of the S30 specimen first reached 0.80 , which was about $30.00 \%$ higher than that of the other specimens. When the load was cycled for the 6 th time under system VI, the damage index of the S30 
TABLE 5: Main parameters of skeleton curves of specimens.

\begin{tabular}{|c|c|c|c|c|c|c|}
\hline \multirow{2}{*}{ Test number } & \multicolumn{4}{|c|}{ Tension } & \multicolumn{2}{|c|}{ Compression } \\
\hline & $P_{y}(\mathrm{kN})$ & $\Delta y(\mathrm{~mm})$ & $P_{\max }(\mathrm{kN})$ & $\Delta u(\mathrm{~mm})$ & $P_{\max }(\mathrm{kN})$ & $\Delta u(\mathrm{~mm})$ \\
\hline S24-I & 193.613 & 6.876 & 276.931 & 15.671 & -223.207 & -15.405 \\
\hline S27-I & 236.701 & 9.712 & 310.712 & 15.454 & -245.411 & -16.605 \\
\hline S30-I & 248.279 & 10.348 & 313.936 & 15.024 & -250.962 & -14.784 \\
\hline S24-II & 187.005 & 7.738 & 253.518 & 13.153 & -226.858 & -13.924 \\
\hline S27-II & 229.278 & 9.627 & 280.554 & 13.153 & -236.005 & -15.450 \\
\hline S30-II & 257.108 & 11.112 & 286.943 & 13.108 & -230.49 & -15.839 \\
\hline 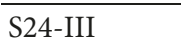 & 183.125 & 4.345 & 303.126 & 26.352 & -218.316 & -15.721 \\
\hline S27-III & 254.281 & 8.896 & 325.905 & 26.184 & -232.554 & -15.998 \\
\hline S30-III & 219.354 & 6.796 & 332.756 & 26.261 & -246.102 & -15.914 \\
\hline S24-IV & 158.046 & 3.511 & 281.098 & 14.245 & -203.501 & -16.422 \\
\hline S27-IV & 248.225 & 10.268 & 305.756 & 14.221 & -222.502 & -15.425 \\
\hline S30-IV & 270.506 & 11.200 & 303.371 & 14.237 & -242.985 & -15.754 \\
\hline $\begin{array}{l}\text { S24-V } \\
\text {. }\end{array}$ & 153.669 & 1.659 & 286.565 & 14.175 & -218.058 & -16.222 \\
\hline S27-V & 233.934 & 7.817 & 299.218 & 14.252 & -225.736 & -16.313 \\
\hline $\mathrm{S} 30-\mathrm{V}$ & 268.177 & 10.835 & 308.000 & 14.1 & -242.265 & -13.889 \\
\hline S24-VI & 95.925 & 1.740 & 293.631 & 14.718 & -254.769 & -16.230 \\
\hline S27-VI & 176.508 & 3.292 & 315.219 & 15.305 & -234.285 & -16.941 \\
\hline S30-VI & 190.305 & 3.980 & 321.312 & 15.365 & -248.633 & -14.996 \\
\hline
\end{tabular}

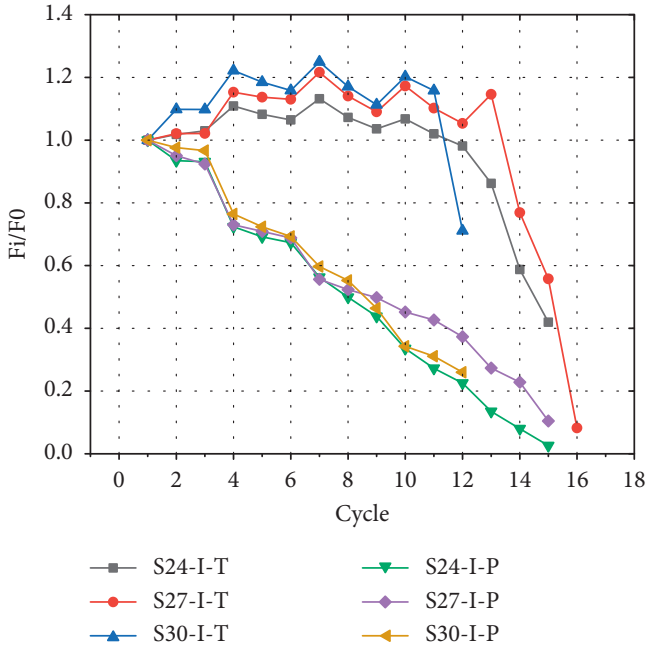

(a)
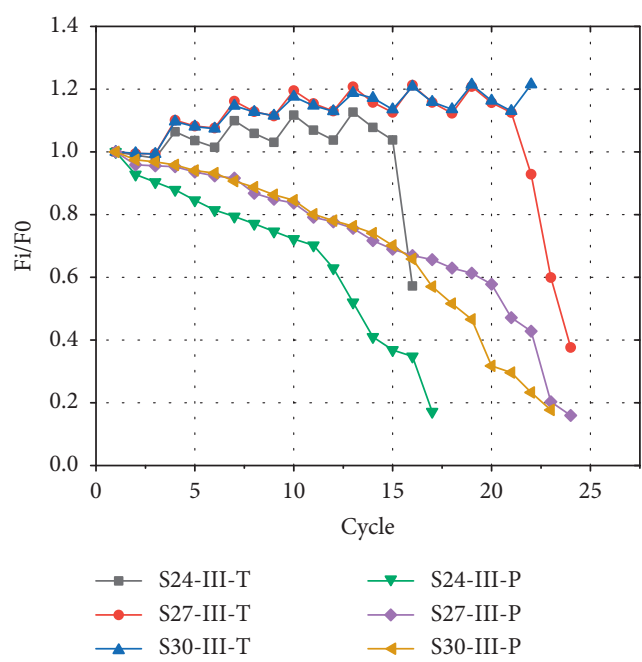

(c)

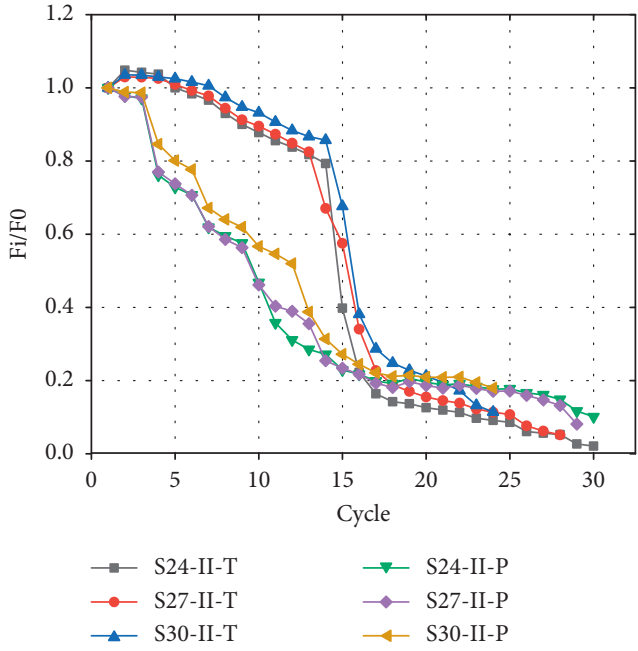

(b)

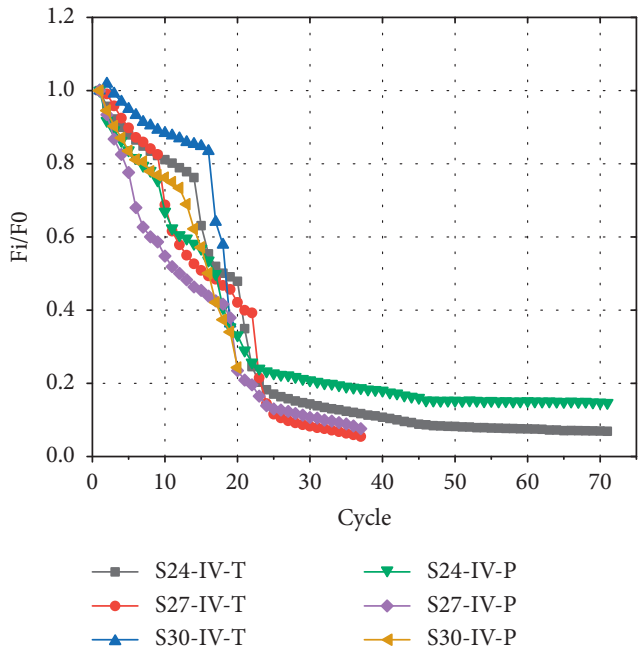

(d)

FIgURE 15: Continued. 


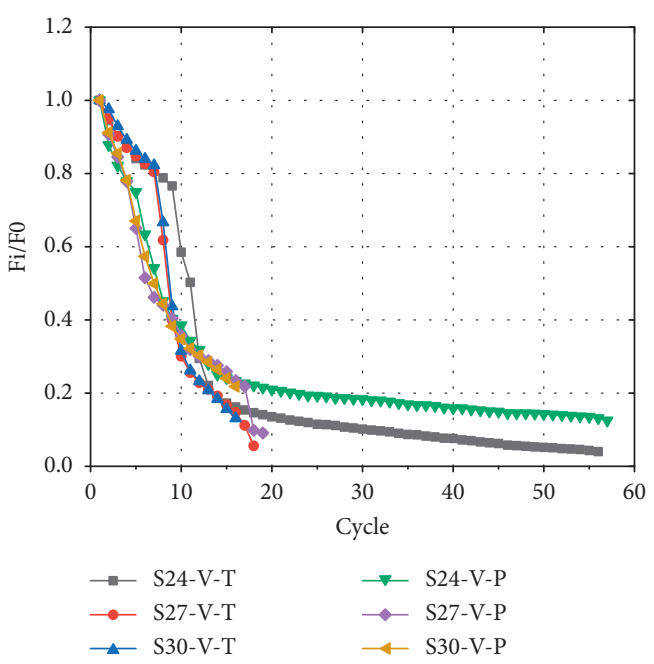

(e)

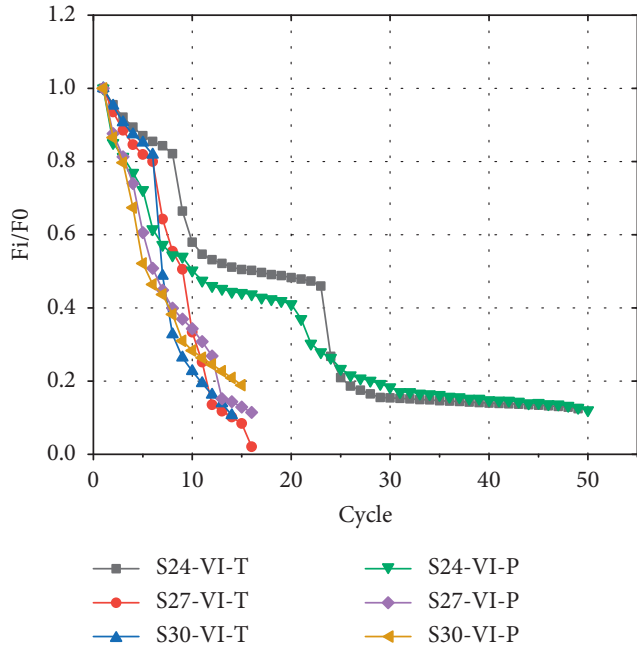

(f)

FIGURE 15: Comparison of bearing-capacity degradation curves. (a) Loading system I. (b) Loading system II. (c) Loading system III. (d) Loading system IV. (e) Loading system V. (f) Loading system VI.

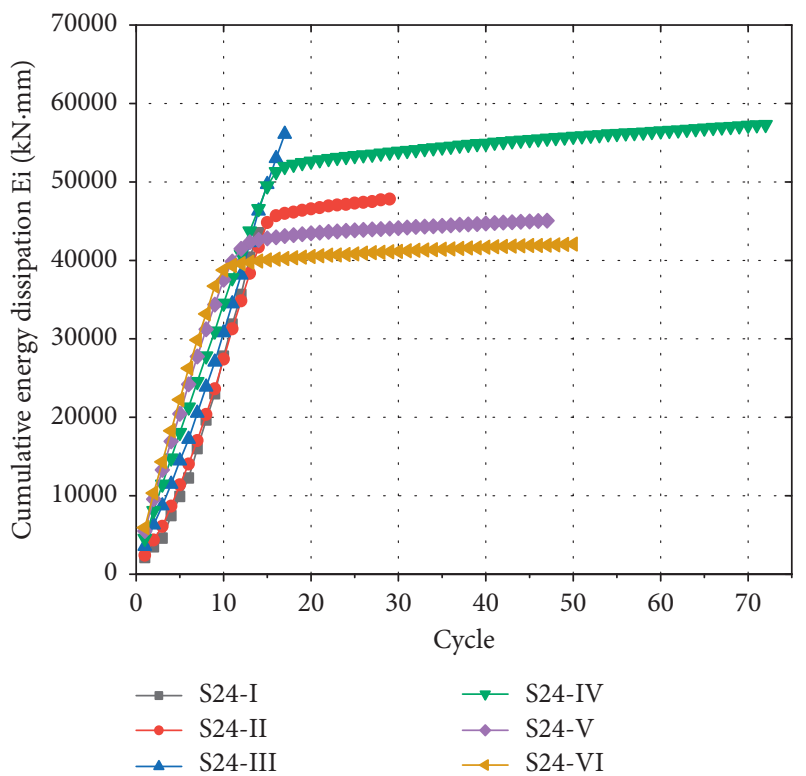

(a)

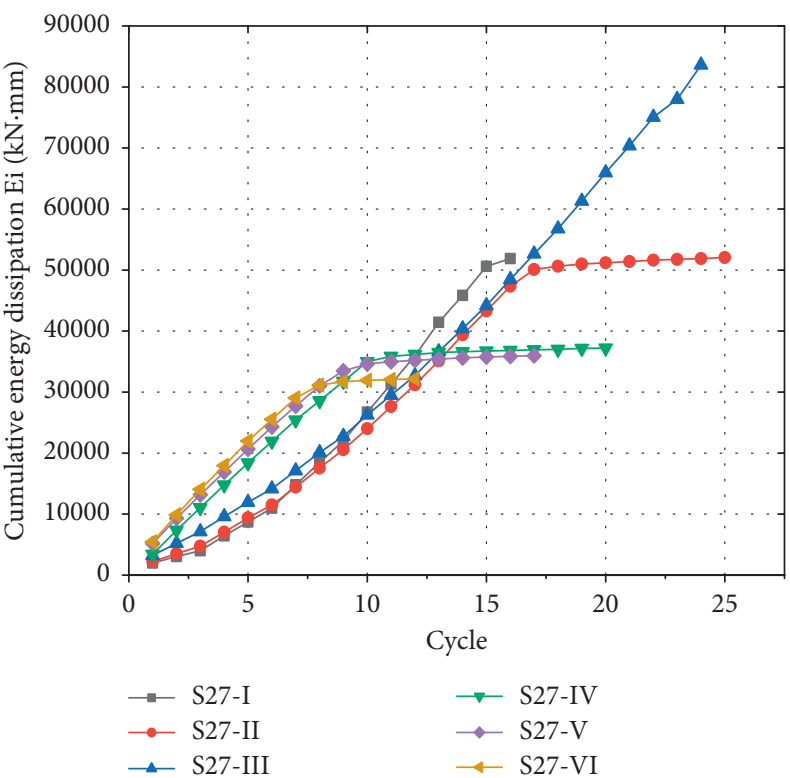

(b)

Figure 16: Continued. 


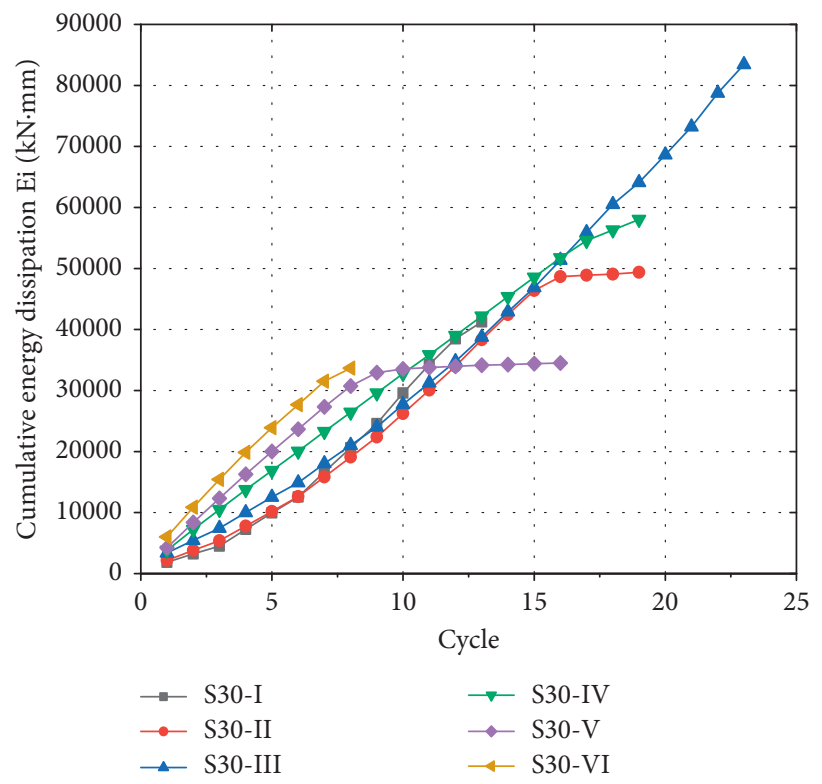

(c)

FIGURE 16: Comparison of cumulative dissipated energy. (a) S24 specimens. (b) S27 specimens. (c) S30 specimens.
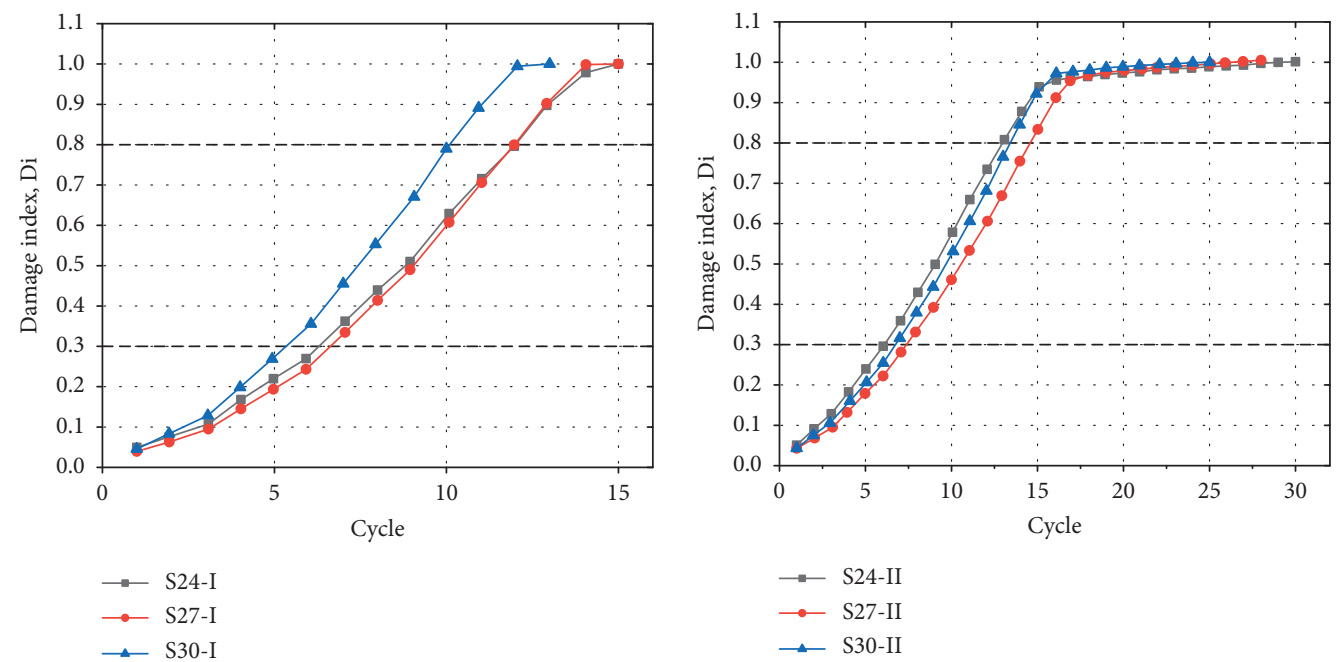

(a)

(b)
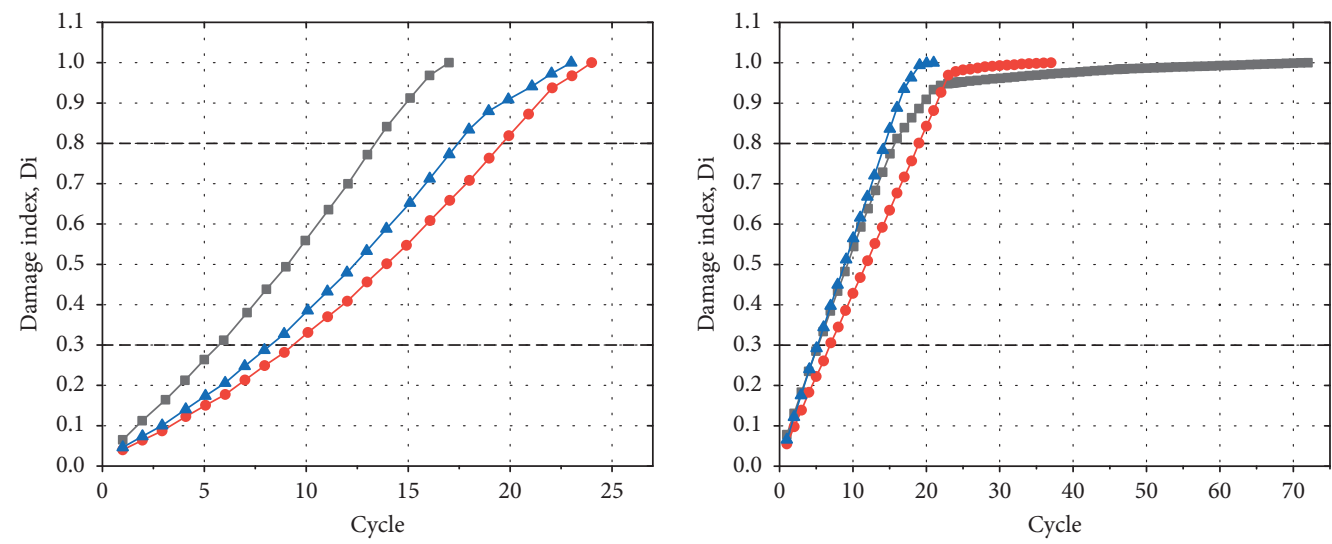

$\rightarrow$ S24-III
$\rightarrow$ S27-III
$\rightarrow$ S30-III$$
\begin{aligned}
& \longrightarrow \text { S24-IV } \\
& \longrightarrow \text { S27-IV } \\
& \multimap \text { S30-IV }
\end{aligned}
$$

(c)

(d)

Figure 17: Continued. 


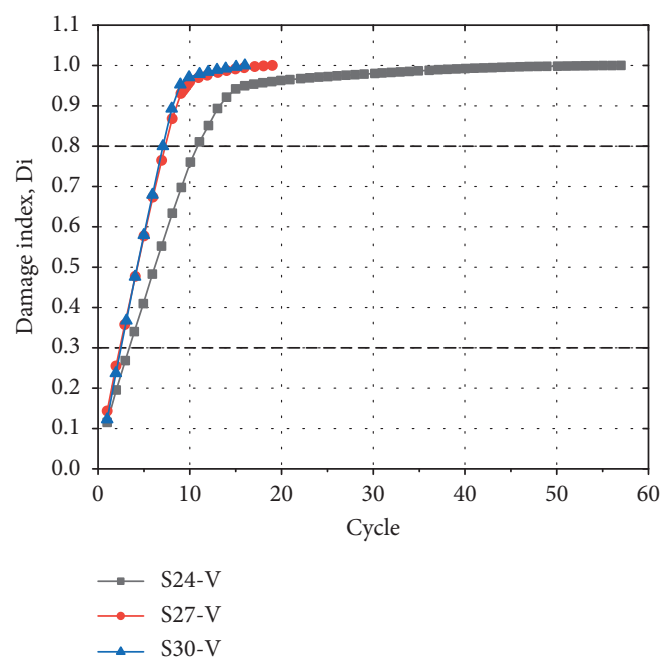

(e)

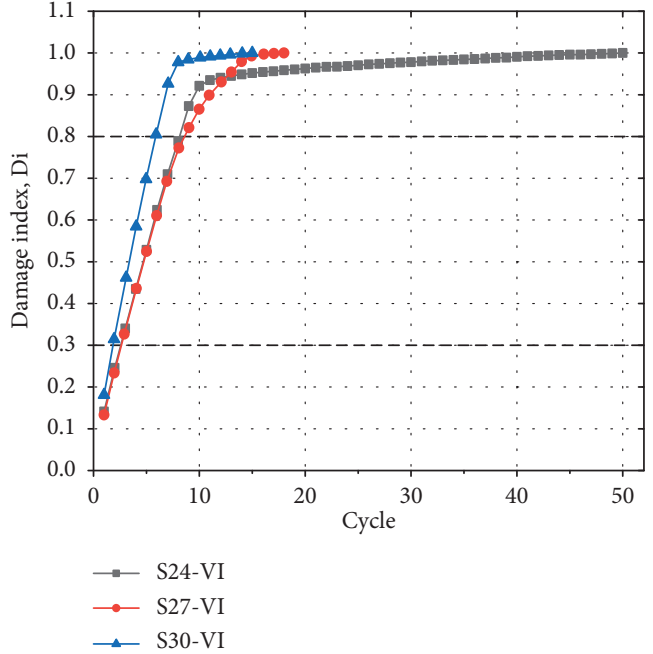

(f)

Figure 17: Damage index comparison. (a) Loading system I. (b) Loading system II. (c) Loading system III. (d) Loading system IV. (e) Loading system V. (f) Loading system VI.

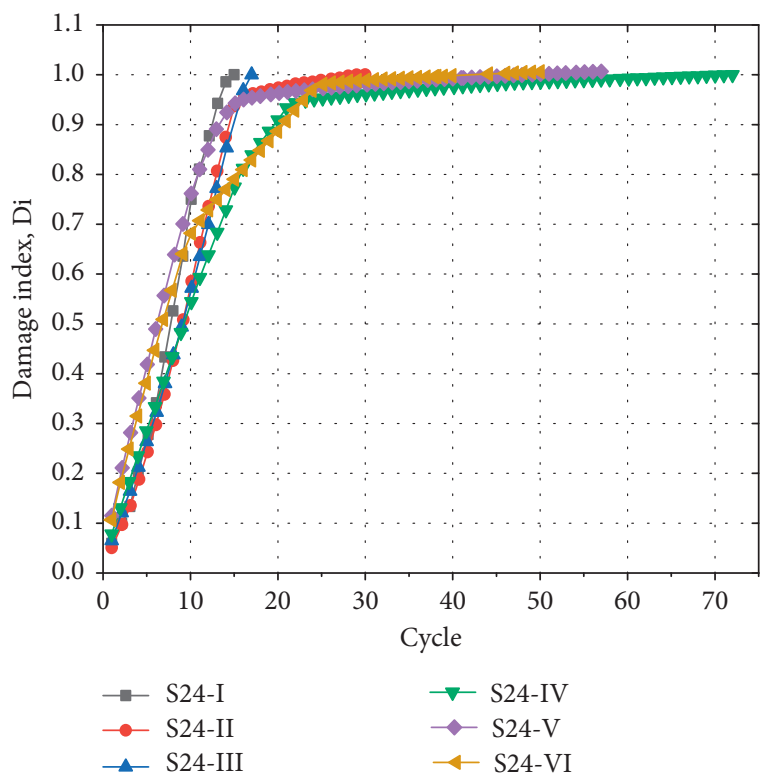

(a)

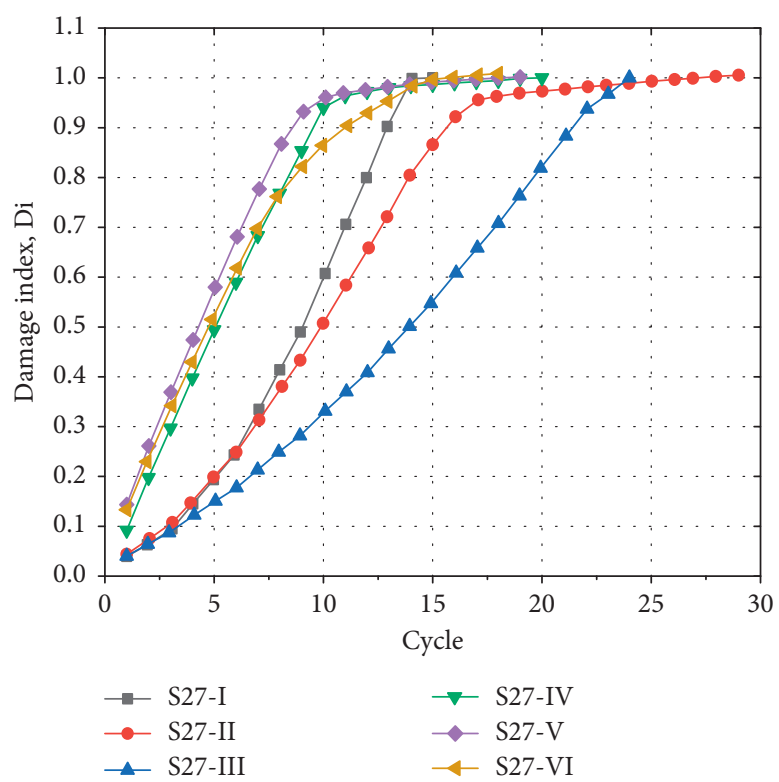

(b)

Figure 18: Continued. 


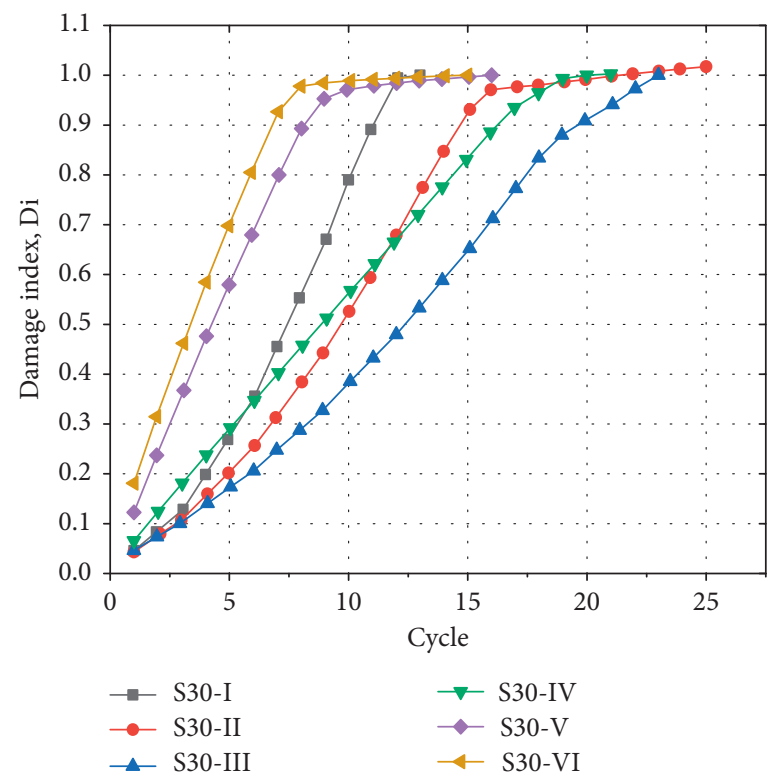

(c)

Figure 18: Damage index comparison. (a) Cumulative damage index of S24. (b) Cumulative damage index of S27. (c) Cumulative damage index of S30.

specimen first reached 0.80 , which was about $30.00 \%$ higher than that of the other specimens.

As a result, the diameters of the bolts at both ends of the specimens had a significant effect on the damage accumulation of the specimens.

3.6.2. Effect of Loading History on Damage. The damage index evolution curves of the same specimen under different loading systems are shown in Figure 18. Comparing the curves in Figures 18(a)-18(c), the damage index evolution of the S27 specimen and the S30 specimen had similar characteristics, while the damage evolution of the S24 specimens was significantly different from that of the S27 and the S30 specimens.

As shown in Figure 18(a), the damage accumulation of the S24 specimens under varying-amplitude and constantamplitude loading systems presented a curve distribution, but the curvature was opposite. When damage index $D$ was less than 0.8 , the numbers of cycles experienced by the specimens under various loading systems were similar when the same damage index was reached. When damage index $D$ was greater than 0.8 , the damage index of S24-I began to exceed the damage index of the other loading systems at the 14 th cycle. The specimen first cracked, and, at the 15th cycle, the specimen was completely broken.

As shown in Figures 18(b) and 18(c), the distributions and trends of the damage evolution curves of the S27 and the S30 specimens under variable-amplitude loading were basically the same. However, the damage evolution curves of the two specimens were different under constant-amplitude loading. The trend of the damage index curves of the S27 specimens with three constant-amplitude loading histories was basically the same. The trends of the damage index curves of S30-V and S30-IV were essentially the same, and the damage accumulation rate of S30-IV was considerably lower than that of the other two loading histories. Therefore, the loading history had a significant effect on the damage index evolution of the specimens. From the cumulative damage curve, when the specimens cracked, the damage indices $D$ were very close to 1.0 , and the energy dissipated by the specimens after cracking was very limited. Therefore, the cracking of the specimens was taken as the limit state for damage to the specimens.

\subsection{Relationship between Bearing-Capacity Degradation and} Cumulative Damage. [19] At present, commonly used hysteretic models include the bilinear model, trilinear model, and pointing-to-peak hysteresis model. These models fail to consider the degradation of the bearing capacity. Based on the damage model established by Ding Yang et al. [10], to evaluate the degree of damage to a steel tube, a bearing-capacity degradation function of the specimens was established, and the results are obtained as follows:

$$
f(D)=1-\frac{F_{i}}{F_{0}} .
$$

Damage index $D$ and bearing-capacity degradation function $f(D)$ obtained from each cycle of the specimen are plotted in Figure 19, and the relationship curve between $f(D)$ and $D$ for the specimen is obtained. By fitting multiple curves, the relationship between the degradation function of the specimen and the damage index is obtained, as shown by the red dotted line in Figure 19.

As shown in Figure 19, there is an exponential relationship between the degradation function $f(D)$ of the bearing capacity and the damage index $D$ of specimens, which is given as follows: 


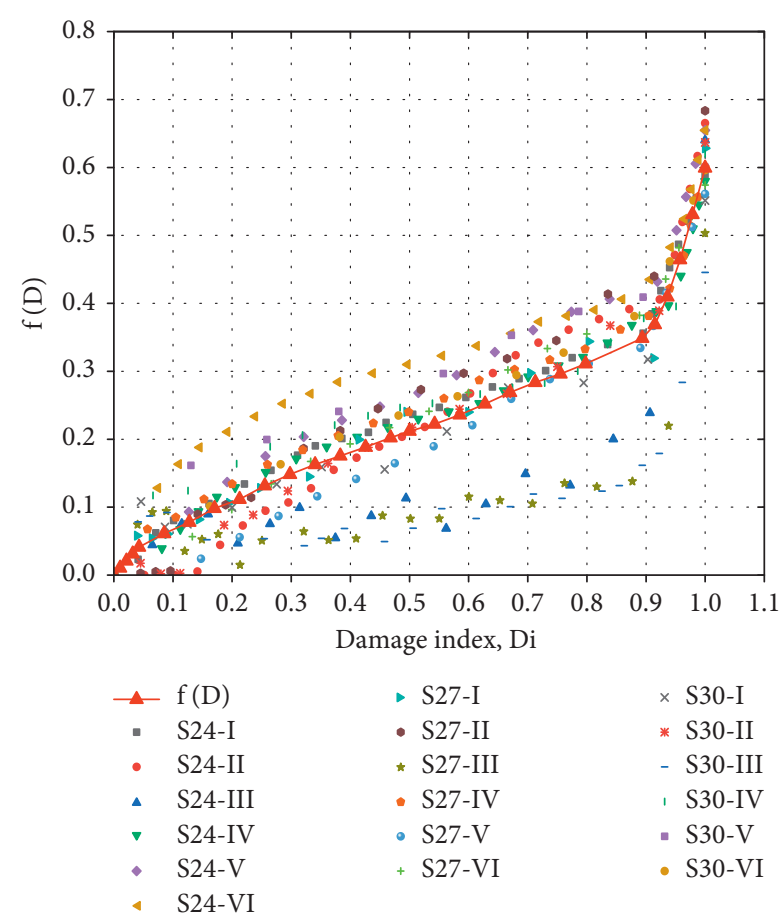

FIGURE 19: Relationship curve between bearing-capacity degradation function and damage index.

$$
\begin{aligned}
f(D) & =\alpha D^{\beta}, \\
\alpha & = \begin{cases}0.37, & 0 \leq D \leq 0.9, \\
0.60, & 0<D<1.0,\end{cases} \\
\beta & = \begin{cases}0.77, & 0 \leq D \leq 0.9, \\
5.64, & 0<D<1.0 .\end{cases}
\end{aligned}
$$

The degradation of the bearing capacity of the assembly consisting of the bolt-sphere joints and steel tubes is related to the stiffness of the joints of the assembly, the loading system, and other factors. By fitting a mass of experimental data, a simple functional relationship between the degradation of the bearing capacity and the damage to the specimens is obtained.

\section{Conclusion}

In this paper, ultralow-cycle fatigue tests of three composite specimens composed of a bolt-sphere and a circular steel tube $(\varphi 88.5 \times 4.0)$ were conducted for various loading systems. The main conclusions of the study are summarised as follows:

(1) Before fracture occurred, all specimens underwent four characteristic stages: entire bending deformation, local dent of the middle area of the specimen, middle cracking of the specimen, and complete fracture of the specimen from the middle. However, owing to the different diameters of the bolt at the end of the rod, the number of cycles experienced by the specimens with the aforementioned characteristics was different. The larger the bolt diameter at the end of the rod, the fewer the number of cycles experienced by the specimen when the characteristic phenomenon occurred. In addition, the fatigue life of the specimen decreased with an increase in the bolt diameter at the end of the rod.

(2) The hysteresis curves of all specimens were relatively full, without obvious pinching phenomena, and the specimens had good energy dissipation capacity. When the displacement amplitude was the same, the bearing capacity decreased with an increase in the number of cycles. It was evident from the skeleton curve that when the displacement amplitude was the same, the compressive and tensile-bearing capacity of the specimen decreased with a decrease in the bolt diameter at the end of the member. This indicated that the bolt diameter at the end of the member had an effect on both the tensile and compressive bearing capacities of the specimen.

(3) According to the curves of bearing-capacity degradation, the bolt diameter at the end of the rod had a significant effect on the bearing-capacity degradation of the specimen. When tested using variable-amplitude loading systems (loading systems I-III), the residual bearing capacity of the S30 specimens was approximately $6 \%-15 \%$ higher than that of the other two specimens. When system IV was adopted in the test, the degree of degradation of the bearing capacity of the S30 specimen was the lowest. Its tensile residual bearing capacity was approximately $7 \%$ higher than that of the other two specimens, and its compressive bearing capacity was approximately 5\% higher than that of the S27 specimen.

(4) According to the damage index evolution curves, the bolt diameter at the end of the rod had a significant effect on the damage accumulation of the specimen. When the test was loaded with three constant-amplitude systems, the cumulative damage index of S30 with the largest bolt diameter at the end of the rod was approximately 0.8 initially, which was approximately $7.54 \%-44.87 \%$ higher than that of S24 and approximately $4.61 \%-32.40 \%$ higher than that of S27.

(5) Based on the test, an equation between the degradation of the bearing capacity and the damage index was derived. The equation has only two parameters, which were easily determined. The degraded model of the bearing capacity is of element level and can be fully realized by finite element programs.

\section{Data Availability}

The data used to support the findings of this study are available from the corresponding author upon request.

\section{Conflicts of Interest}

The authors declare that they have no conflicts of interest. 


\section{Acknowledgments}

This research was financially supported by the National Natural Science Foundation of China (51578358). The authors are thankful to Dr. Shizhe Chen for his useful suggestions and careful revision of this paper.

\section{References}

[1] J. Dai, Z. Qu, C. Zhang, and X. Weng, "Preliminary investigation of seismic damage to two steel space structures during the 2013 Lushan earthquake," Earthquake Engineering and Engineering Vibration, vol. 12, no. 3, pp. 497-500, 2013.

[2] J. H. Xing, M. Lu, H. W. Li, Y. M. Zhao, and Y. Yu, "The seismic damage investigation and phenomenon analysis of space grid structures in lushan ms 7.0 earthquake," Applied Mechanics and Materials, vol. 501-504, pp. 1535-154, 2014.

[3] H. Li, Planning and Design of City Disaster Earthquake Shelter and Disaster Relief Base, Construction Industry Press, Beijing, China, 2013, in Chinese.

[4] H. Li, H. Zhao, Y. Zhao, and X. Shu, "Study on planning for the indoor-earthquake-shelter in city and town," Advanced Science Letters, vol. 4, no. 8, pp. 2654-2665, 2011.

[5] S. A. Mahin, "Lessons from damage to steel buildings during the Northridge earthquake," Engineering Structures, vol. 20, no. 4-6, pp. 261-270, 1998.

[6] H. Kuwamura, "Fracture of steel during an earthquake-stateof-the-art in Japan," Engineering Structures, vol. 20, no. 4-6, pp. 310-322, 1998.

[7] S. Dhar, R. Sethuraman, and P. M. Dixit, "A continuum damage mechanics model for void growth and micro crack initiation," Engineering Fracture Mechanics, vol. 53, no. 6, pp. 917-928, 1996.

[8] S. Dhar, P. M. Dixit, and R. Sethuraman, "A continuum damage mechanics model for ductile fracture," International Journal of Pressure Vessels \& Piping, vol. 77, no. 6, pp. 335344, 2000.

[9] H. R. Amiri, A. A. Aghakouchak, S. Shahbeyk, and M. D. Engelhardt, "Finite element simulation of ultra low cycle fatigue cracking in steel structures," Journal of Constructional Steel Research, vol. 89, no. 5, pp. 175-184, 2013.

[10] Y. Ding, M. Wu, L. Xu, and Z. Li, "Seismic damage evolution of steel columns considering damage accumulation," Journal of Building Structures, vol. 32, no. 7, pp. 112-117, 2011.

[11] N. Gui-bo, Z. Xu-dong, and F. Feng, "Spatial hysteretic experiment for circular steel pipe," Advanced Materials Research, vol. 422, pp. 169-174, 2010.

[12] F. Feng, G. Nie, and X. Zhi, "Constitutive model of circular steel tubes under complicated cyclic load," Journal of Building Structures, vol. 32, no. 8, pp. 59-68, 2011.

[13] N. Gui-bo, F. Feng, and Z. Xu-dong, "Study on the failure mechanism of single-layer cylindrical shell under seismic motion based on refined constitutive model," China Civil Engineering Journal, vol. 45, no. S1, pp. 30-35, 2012.

[14] J. M. Goggins, B. M. Broderick, A. Y. Elghazouli, and A. S. Lucas, "Experimental cyclic response of cold-formed hollow steel bracing members," Engineering Structures, vol. 27, no. 7, pp. 977-989, 2005.

[15] S. Salawdeh and J. Goggins, "Numerical simulation for steel brace members incorporating a fatigue model," Engineering Structures, vol. 46, pp. 332-349, 2013.

[16] F. Fan, H. Ma, G. Chen, and S. Shen, "Experimental study of semi-rigid joint systems subjected to bending with and without axial force," Journal of Constructional Steel Research, vol. 68, no. 1, pp. 126-137, 2012.

[17] M. R. Chenaghlou and H. Nooshin, "Axial force-bending moment interaction in a jointing system," Journal of Constructional Steel Research, vol. 113, pp. 277-285, 2015.

[18] Q. Xu, S. Zheng, and Y. Fan, "Experimental study on seismic damage of steel frame joints under large displacement," Journal of Harbin Engineering University, vol. 40, no. 2, pp. 70-75, 2019.

[19] M. Wang, Damage and Degradation Behaviors of Steel Frames under Severe Earthquake, Tsinghua University, Beijing, China, 2013. 


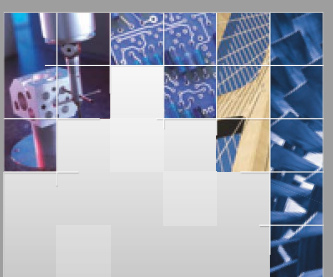

\section{Enfincering}
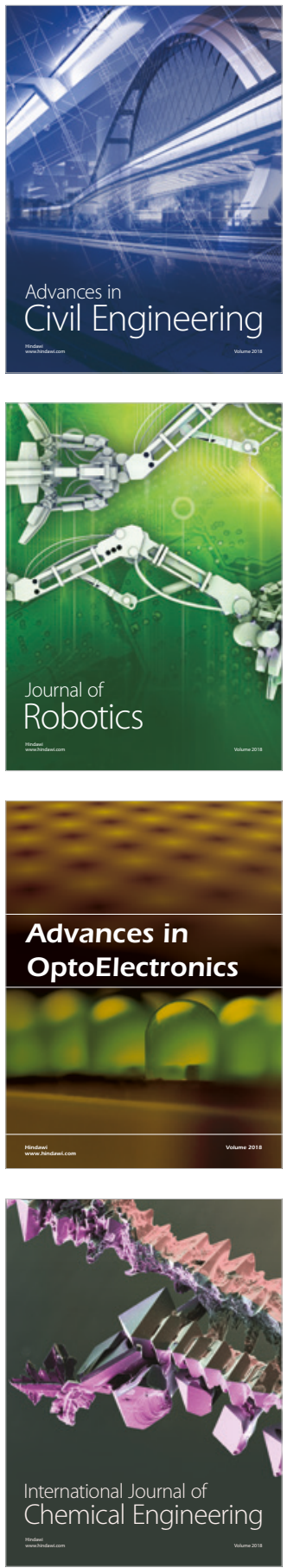

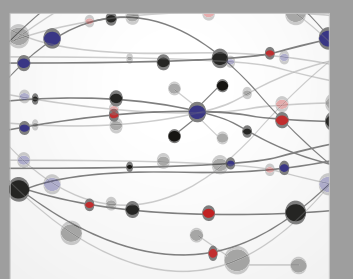

\section{Rotating \\ Machinery}

The Scientific World Journal

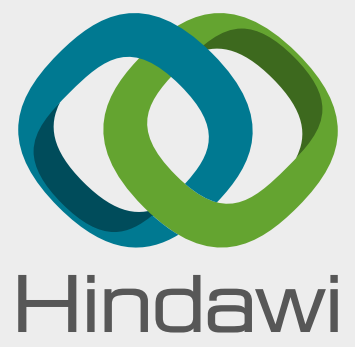

Submit your manuscripts at

www.hindawi.com
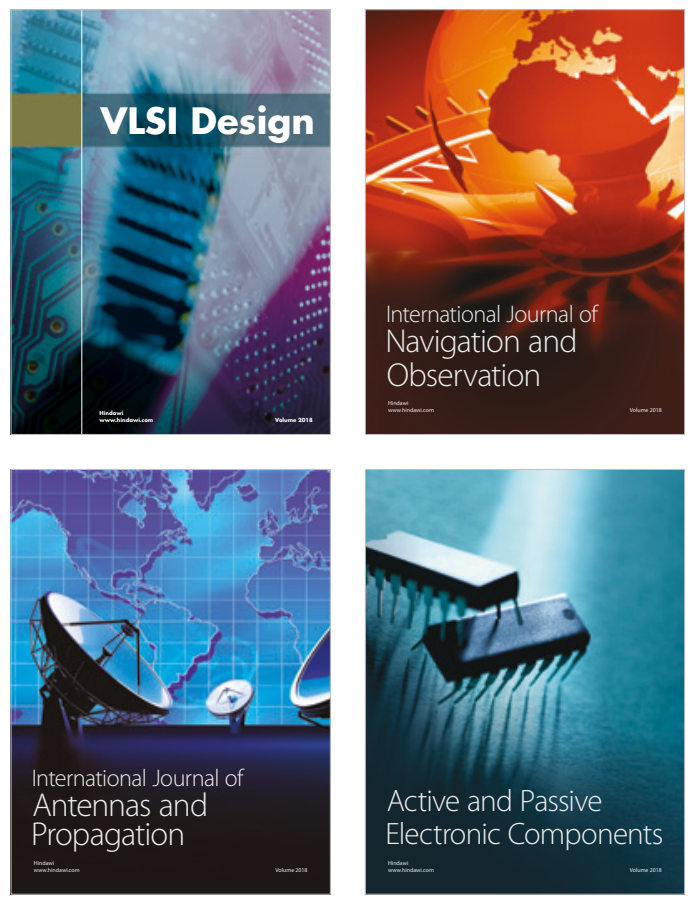
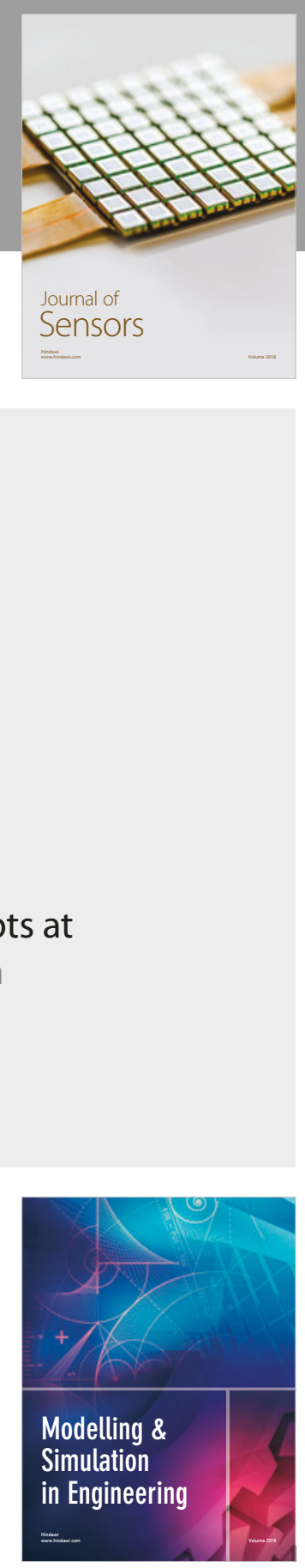

\section{Advances \\ Multimedia}
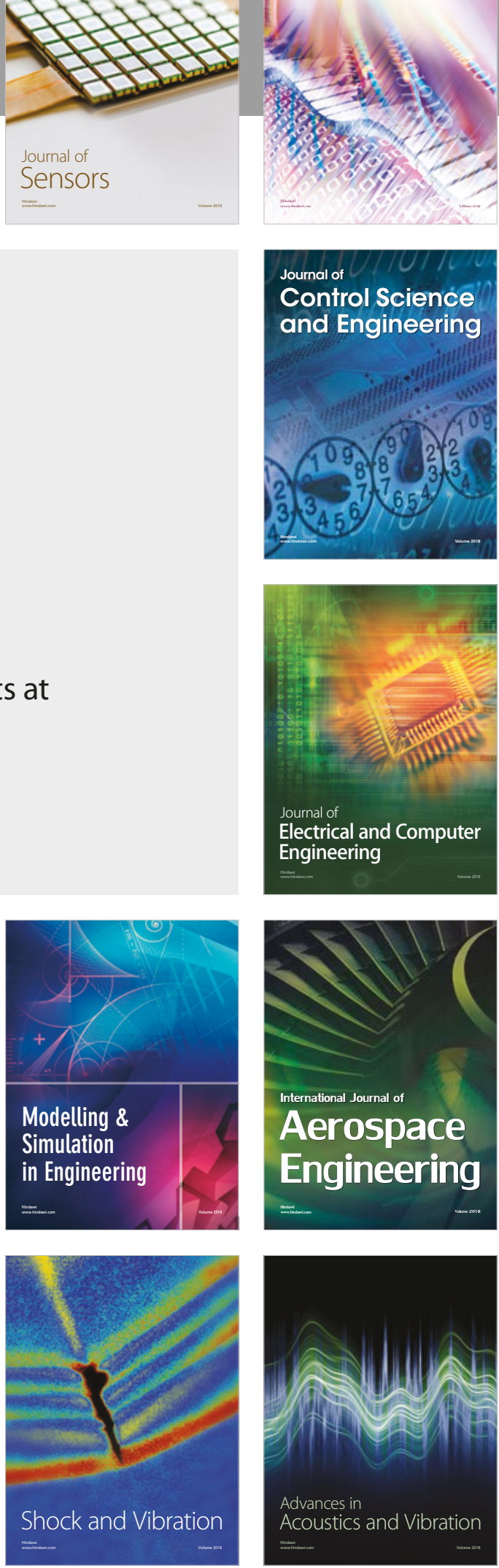